SNS 102030100-TR0001-ROO

ALARA Review of the Spallation Neutron Source Accumulator Ring and Transfer Lines 
This report was prepared as an account of work sponsored by an agency of the United States government. Neither the United States government nor any agency thereof, nor any of their employees, makes any warranty, express or implied, or assumes any legal liability or responsibility for the accuracy, completeness, or usefulness of any information, apparatus, product, or process disclosed, or represents that its use would not infringe privately owned rights. Reference herein to any specific commercial product, process, or service by trade name, trademark, manufacturer, or otherwise, does not necessarily constitute or imply its endorsement, recommendation, or favoring by the United States government or any agency thereof. The views and opinions of authors expressed herein do not necessarily state or reflect those of the United States government or any agency thereof. 
SNS 102030100-TR0001-R00

ORNL/TM-2000/206

\title{
ALARA REVIEW OF THE SPALLATION NEUTRON SOURCE ACCUMULATOR RING AND TRANSFER LINES
}

\author{
M. Jonathan Haire \\ Gloria T. Mei
}

Date Published: March 2003

Prepared by

Oak Ridge National Laboratory

Oak Ridge, Tennessee 37831

under contract DE-AC05-00OR22725

Prepared for the

U.S. Department of Energy

Office of Science

\section{UT-BATTELLE, LLC}

managing

Spallation Neutron Source activities at

Argonne National Laboratory

Brookhaven National Laboratory

Thomas Jefferson National Accelerator Facility Lawrence Berkeley National Laboratory

Los Alamos National Laboratory

Oak Ridge National Laboratory

under contract DE-AC05-00OR22725

for the

U.S. DEPARTMENT OF ENERGY 


\section{CONTENTS}

Page

LIST OF FIGURES ....................................................................................... iv

LIST OF TABLES …............................................................................................ iv

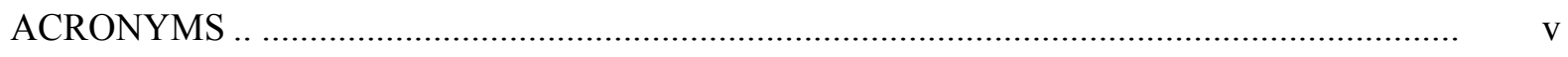

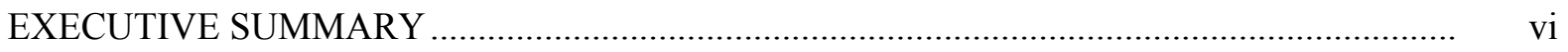

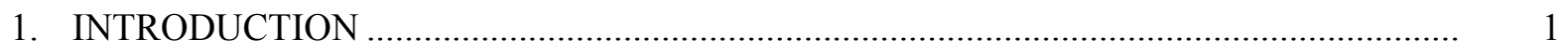

2. DESCRIPTION OF THE SNS SITE, FACILITIES, EQUIPMENT, AND

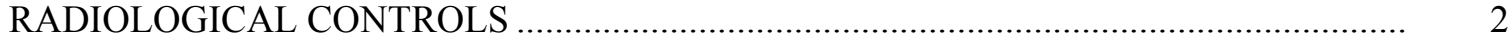

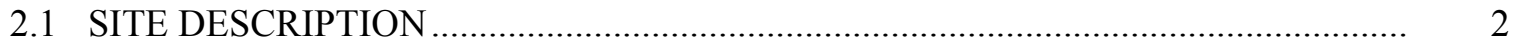

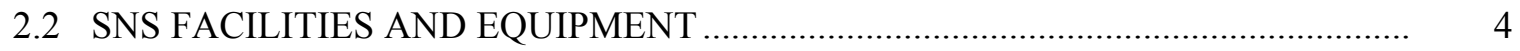

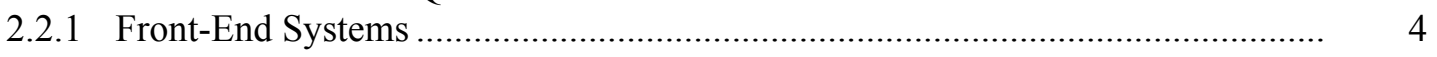

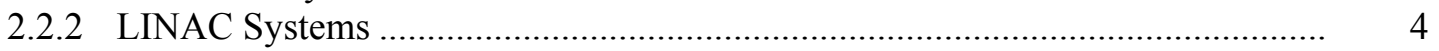

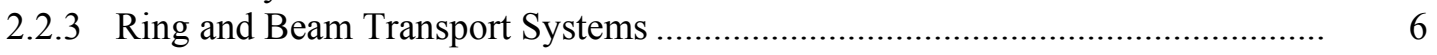

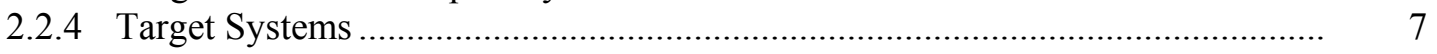

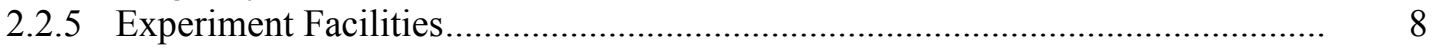

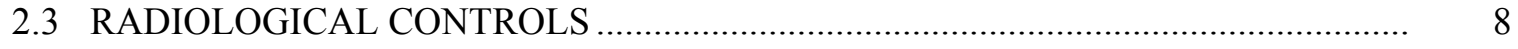

2.3.1 Radiation Safety Committee ……....................................................................... 8

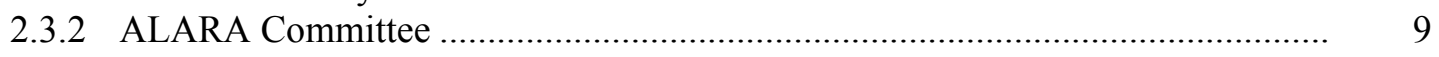

2.3.3 ORNL Accelerator Safety Review Committee ……...................................... 9

2.3.4 ORNL Radiation Protection Involvement .................................................... 9

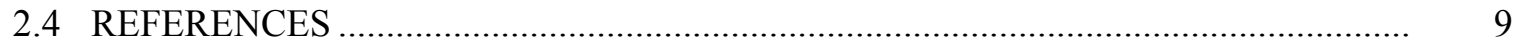

3. RADIATION PROTECTION DESIGN CRITERIA AND RADIATION LEVEL

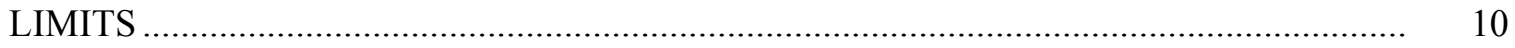

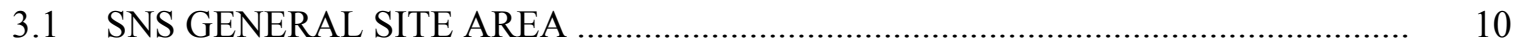

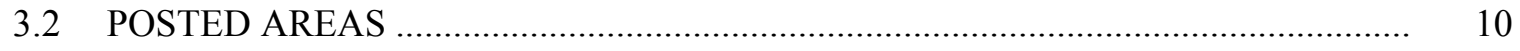

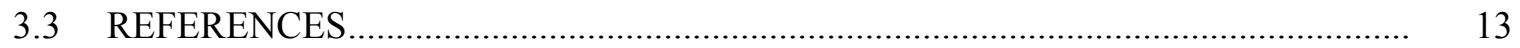

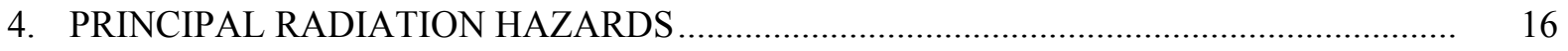

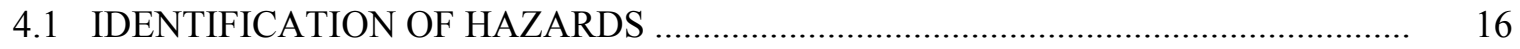

4.2 SOURCE TERM AND EARTH BERM SHIELDING ............................................. 16

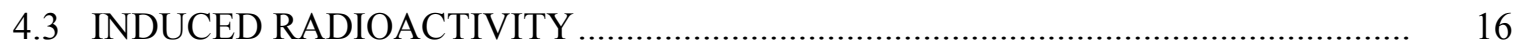

4.3.1 Residual Radiation in Machine Components .................................................... 17

4.3.2 Induced Activity in Cooling and Fire Protection Water..................................... 22

4.3.3 Induced Activity in Air...................................................................... 22

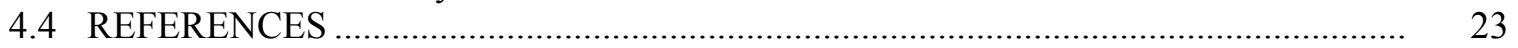




\section{CONTENTS (continued)}

Page

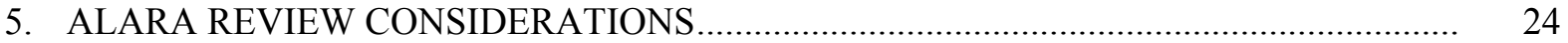

5.1 CHARACTERIZATION OF RADIATION FIELDS AND POTENTIAL DOSES

5.2 SHIELDING

5.3 EQUIPMENT SELECTION

5.4 ACCESS CONTROL

5.5 RADIATION MONITORING INSTRUMENTATION

5.6 CONFINEMENT STRUCTURE AND VENTILATION SYSTEM

5.7 CONTAMINATION CONTROLS AND DECONTAMINATION AND DECOMMISSIONING

5.8 REFERENCES

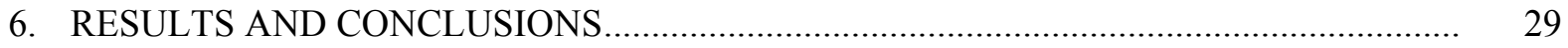

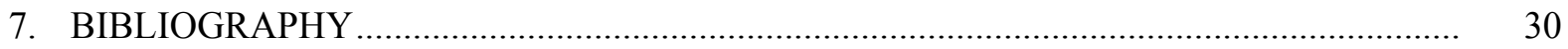

APPENDIX A: ALARA DESIGN CONSIDERATIONS ….................................................... A-1 


\section{LIST OF FIGURES}

Figure $\quad$ Page

2.1 Location of SNS site within the Oak Ridge Reservation ............................................... 3

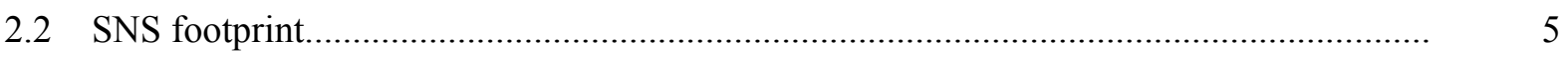

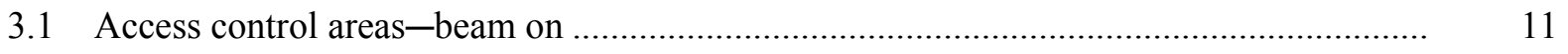

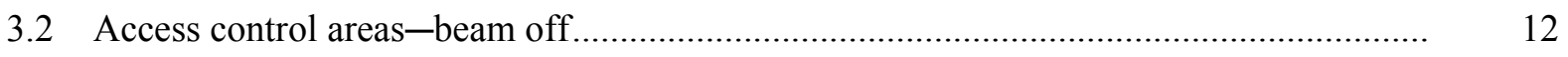

4.1 Quadrupole magnet with 2-m-long vacuum chamber (dose in rem/hour) ........................ 19

4.2 Schematic of collimator components (horizontal section) .............................................. 19

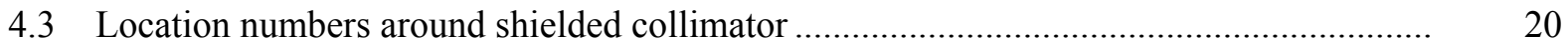

\section{LIST OF TABLES}

Table $\quad$ Page

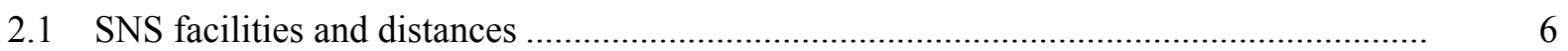

2.2 Radiation Safety Committee membership.................................................................. 8

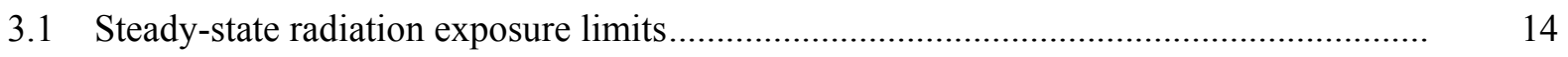

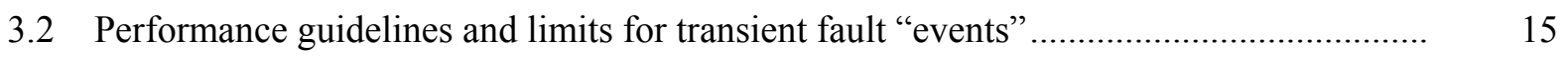

4.1 Dose as a function of distance from HEBT, ring, and RTBT vacuum chamber

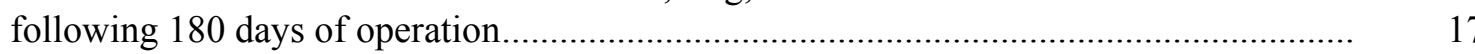

4.2 Doses for shielded collimator (standard configuration) with and without movable shield

4.3 Reduction in gamma intensity (and dose) with time following shutdown......................... 22

4.4 Air activation during accelerator operation, assuming routine ventilation (although though this is not planned) 


\section{ACRONYMS}

AGS advanced gradient synchrotron

ALARA as low as reasonably achievable

ASRC Accelerator Safety Review Committee

BNL Brookhaven National Laboratory

CCDTL cavity coupled drift-tube linac

CCL cavity coupled linac

DOE U.S. Department of Energy

DTL drift-tube linac

ES\&H environment, safety, and health

FODO Focus Zero Defocus Zero

FSAR final safety analysis report

HEBT high-energy beam transport

LANL Los Alamos National Laboratory

LINAC linear accelerator

ORNL Oak Ridge National Laboratory

ORR Oak Ridge Reservation

OSSD Operational Safety Services Division

PLC programmable logic controllers

PPS personnel protection systems

rf radio frequency

RTBT ring-to-transfer beam transport

RWP radiological work permit

SNS Spallation Neutron Source

SRD System Requirements Document 


\section{EXECUTIVE SUMMARY}

The Spallation Neutron Source (SNS) is designed to meet the growing need for new tools that will deepen our understanding in materials science, life science, chemistry, fundamental and nuclear physics, earth and environmental sciences, and engineering sciences. The SNS is an accelerator-based neutronscattering facility that when operational will produce an average beam power of $2 \mathrm{MW}$ at a repetition rate of $60 \mathrm{~Hz}$. The accelerator complex consists of the front-end systems, which will include an ion source; a 1-GeV full-energy linear accelerator; a single accumulator ring and its transfer lines; and a liquid mercury target. This report documents an as-low-as-reasonably-achievable (ALARA) review of the accumulator ring and transfer lines at their early design stage.

An ALARA working group was formed and conducted a review of the SNS ring and transfer lines at the $-25 \%$ complete design stage to help ensure that ALARA principles are being incorporated into the design. The radiological aspects of the SNS design criteria were reviewed against regulatory requirements and ALARA principles. Proposed features and measures were then reviewed against the SNS design criteria. As part of the overall review, the working group reviewed the design manual; design drawings and process and instrumentation diagrams; the environment, safety, and health manual; and other related reports and literature. The group also talked with SNS design engineers to obtain explanations of pertinent subject matter.

The ALARA group found that ALARA principles are indeed being incorporated into the early design stage. Radiation fields have been characterized, and shielding calculations have been performed. Radiological issues are being adequately addressed with regard to equipment selection, access control, confinement structure and ventilation, and contamination control. Radiation monitoring instrumentation for worker and environment protection are also being considered-a good practice at this early design stage.

The ring and transfer lines are being designed for hands-on maintenance. The SNS beam loss criteria, which determine radiation dose design, are a factor of $\sim 30$ lower than the lowest that has been achieved at any existing proton synchrotron and accumulator rings. This demonstrates that ALARA considerations are an important part of SNS design.

A noteworthy example of the ALARA principal being incorporated into the SNS is the hybrid ring lattice design recently approved by the SNS change control process. The new lattice design increases calculated acceptance by about $50 \%$ and improves the expected collimator efficiency from 80 to $95 \%$. As a result, the expected calculated beam loss rate, and resulting radiation dose rates, are significantly improved.

Another major design change with ALARA implications was the change from an alpha to an omega configuration for the high-energy beam transport (HEBT) system, ring, and ring-to-target beam transport (RTBT) system. Because of this change, the ring and transfer lines will have crane coverage, eliminating the need for personnel to be near activated equipment for repair and removal. By using the crane, extensive shielding can be placed around highly radioactive equipment (e.g., collimators), and the equipment can be moved by remote control. As part of the change from an alpha to omega configuration, the tunnel width was increased by $2 \mathrm{ft}$. This increased width will allow easier access to failed equipment, reducing radiation exposure time to workers during maintenance and repair. In addition, a personnel entrance was added to the ring between the HEBT and RTBT so that personnel will not have to enter this area directly through the HEBT or RTBT. This addition will shorten the travel distance, and therefore the time, that personnel performing maintenance work on radioactive equipment will need to be in the area, reducing potential dose. In the RTBT beam line, a hatchway will be placed above the collimators and quad doublet magnets near the target to facilitate their removal. This design was chosen in lieu of a track system that would require removal of all equipment near the target when replacing collimators or quads.

This report describes many other examples where ALARA principals have been applied to the SNS design. The strongest, clearest indication that ALARA principles are being incorporated into the design is 
that knowledgeable, experienced individuals who are conscious of ALARA issues participate at every design review and at all levels of design. 


\section{INTRODUCTION}

The Spallation Neutron Source (SNS) is a new accelerator-based neutron-scattering research facility under construction in Oak Ridge, Tennessee. The SNS will serve the needs of scientists and researchers from universities, industry, and private and federal laboratories from the United States and beyond. Neutron-based research is becoming an increasingly essential tool in the physical, chemical, and biological sciences. To produce the neutrons needed for such research at SNS, an accelerator system will be used to deliver short (microsecond) pulses of high-energy protons that will be accumulated in a ring and delivered onto a liquid mercury target. The impact of protons onto the neutron-dense mercury "spalls off" neutrons, which are guided to various specially designed experiment stations. The SNS is scheduled to be completed in 2006 at a cost of $\$ 1.4 \mathrm{~B}$.

This report documents an as-low-as-reasonably-achievable (ALARA) working group's review of the SNS accumulator ring and transfer lines to ensure that ALARA principals are being incorporated. The radiological aspects of the design criteria for normal operations, maintenance, and anticipated upset conditions were reviewed against regulatory requirements and ALARA principles. The corresponding proposed features or measures for SNS were then reviewed against the design criteria.

As part of the review, the ring ALARA working group became familiar with key elements of the SNS accumulator ring and transport lines and the basis of design for them. The group reviewed the design manual; drawings and process and instrumentation diagrams; environment, safety, and health (ES\&H) manual; and related reports and literature. The group also talked with SNS design engineers to obtain explanations of pertinent subject matter. Numerous discussions were also held with SNS personnel from Brookhaven National Laboratory, where the primary ring design is being conducted.

The SNS is designed for hands-on maintenance, as opposed to remote maintenance. This design philosophy requires that the average uncontrolled beam loss be limited to $\sim 1 \mathrm{~W}$ of beam power per tunnel meter. For an accumulator ring with a circumference of $220 \mathrm{~m}$, this corresponds to an average fraction beam loss of $\sim 10^{-4}$ at $1 \mathrm{GeV}$ beam energy. The lowest achievable beam loss, among existing proton synchrotrons and accumulator rings, is about $3 \mathrm{H} 10^{-3}$ at the Proton Storage Ring at Los Alamos National Laboratory (LANL). However, SNS is designed with an estimated beam loss of $10^{-4}$. SNS is committed to ALARA principles as demonstrated by this low beam loss design criterion. 


\section{DESCRIPTION OF THE SNS SITE, FACILITIES, EQUIPMENT, AND RADIOLOGICAL CONTROLS}

This section provides a description of the SNS site characteristics and facilities, including the location of major buildings and their projected occupancy levels. Descriptions of radiological control policies, ALARA organizations, and administration are also included.

\subsection{SITE DESCRIPTION}

The SNS site is located atop Chestnut Ridge on the X-10 portion of the Oak Ridge Reservation (ORR), -1.75 miles $(2.8 \mathrm{~km})$ northeast from the center of Oak Ridge National Laboratory (ORNL). The site is accessed via Chestnut Ridge Road, across from the 7000 area at ORNL. The SNS buildings will be built on Chestnut Ridge about 1,030 to 1,050 ft above sea level. The footprint for the project extends along a long, wide ridge top at the eastern end of Chestnut Ridge. The major buildings needed for the operational part of the facility - the linear accelerator (LINAC), transport line, ring, and target-are notched into the south side of the ridge.

The ORR consists of about 37,000 acres, with three major industrial complexes located in adjacent valleys: the K-25 site (East Tennessee Technology Park), the X-10 site (ORNL), and the Y-12 Plant site. The ORNL site is about 6 miles southwest of the commercial and population center of the city of Oak Ridge and about 23 miles west of the center (downtown) of the city of Knoxville. The location of the SNS within the ORR is shown on Fig. 2.1.

The closest ORR boundary to the SNS site is about 7,500 $\mathrm{ft}$ to the northwest on the south side of East Fork Ridge. The closest point where private residences can be built (some already exist in this area) is about 7,500 ft to the northwest. The general public is allowed routine access to several ORR locations, and several unrestricted roads traverse the reservation. The public road closest to the SNS site is Bethel Valley, which runs in an east-west direction about 1 mile to the south. Because Bethel Valley Road is closer to the SNS site than the ORR boundary and any other locations on the reservation where the public is allowed routine access, it is the point where the consequences to the public of short-term airborne normal operation and accident releases are evaluated. The point of closest approach on Bethel Valley Road is about 4,600 $\mathrm{ft}(1400 \mathrm{~m})$ to the south of the SNS site.

Access to ORNL is from Bethel Valley Road to the south and Tennessee State Highway 95, which runs in a north-south direction west of ORNL. All access roads that lead directly onto the ORNL site are posted and are closed to the general public. ORNL has the authority to control access to Bethel Valley Road and Highway 95 in the event of an emergency.

The average temperatures recorded vary from about $37 \mathrm{EF}$ in January to $77 \mathrm{EF}$ in July. Temperatures above 100EF (105EF maximum) have been experienced from June through September. Temperatures of $5 \mathrm{EF}$ or below (-17EF minimum) have been experienced from November through March.

The average annual precipitation recorded is about 54 in., with a maximum annual of $76.33 \mathrm{in}$. and a minimum annual of 37.43. The greatest monthly total has been 19.27 in., with a maximum of 7.48 in. during a 24-h period. The normal season snowfall recorded at the City of Oak Ridge station is 11.1 in., with a single season maximum of $41.4 \mathrm{in}$.

The wind direction above the ridge tops and within the valleys at ORNL tends to be aligned with the orientation of the valleys. The prevailing wind is from the southwest, with a secondary maximum from the northeast during the winter, spring, and summer months. This situation is reversed in the fall, with the prevailing wind coming from the northeast. Flow across the valleys is infrequent. The average wind speed recorded at the $10 \mathrm{~m}$ height on the ORNL Bethel Valley area meteorological tower-2 during the period of record from 1984 through 1996 was also $4.4 \mathrm{mph}$. 


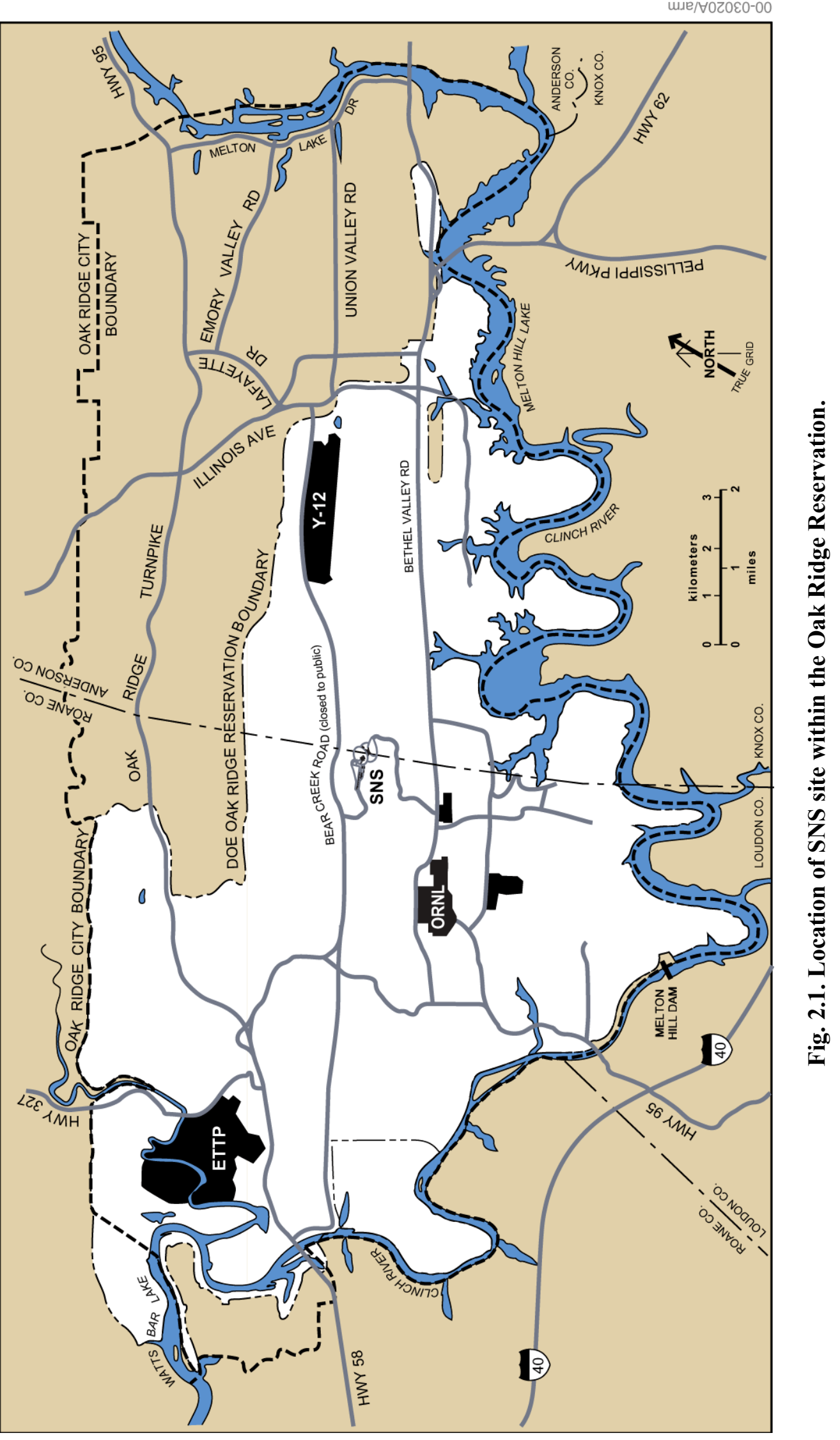


Surface water at the SNS site consists of a small perennial stream that acts as headwater to White Oak Creek. This unnamed tributary flows southeast from the valley below the SNS footprint on Chestnut Ridge into the ORNL main plant area. Flow diminishes to zero at the elevation of the proposed SNS site. Two additional drainages northeast and southwest of the site dissect the scarp face of Chestnut Ridge and flow northwesterly into Bear Creek. While these drainages may receive runoff from the SNS footprint area, the footprint does not overlay the actual stream channels.

The SNS site is not within a floodplain, and widespread flooding is unlikely for a site several hundred feet above the valley floor. The site development plans include a basin to retard runoff from graded areas during a severe rain event.

No significant undesired local ponding would occur on the immediate SNS site since the site is located on a ridge top and will be graded to preclude undesired water accumulation. A drainage basin will be provided to control rainwater drainage from the site. Because of the site's location atop Chestnut Ridge, significant local site flooding is not credible.

Groundwater at the site is observed at a depth of $>60 \mathrm{ft}(18 \mathrm{~m})$. Note that groundwater levels vary significantly at the site depending on height above the valley floor and seasonal and climatic conditions.

The hydrology of the ORR has been described by Moore (1989). A detailed environmental description is contained in Fitzpatrick (1982) and Boyle et al. (1982). A detailed site description is contained in LMER (2000), Fitzpatrick (1982), and Boyle et al. (1982).

\subsection{SNS FACILITIES AND EQUIPMENT}

The facilities that comprise the SNS are shown in Fig. 2.2 and are identified in Table 2.1, along with the approximate closest distances from other buildings.

\subsubsection{Front-End Systems}

The 2.5-MeV beam from the radio-frequency (rf) quadrupole is transported through the mediumenergy beam transport for matching and injection into the drift-tube LINAC (DTL).

\subsubsection{Linac Systems}

The LINAC receives $2.5 \mathrm{MeV}$ of $\mathrm{H}$ ! injected from the front-end systems and accelerates the negative ions to $1.0 \mathrm{GeV}$ for delivery to the high-energy beam transport (HEBT) system. The LINAC consists of three types of rf accelerating structures: the DTL, coupled-cavity DTL (CCDTL), and coupled-cavity LINAC (CCL). The DTL operates at 402.5 MHz and accelerates the beam from 2.5 MeV to $20 \mathrm{MeV}$. The remaining lattice structures, the CCDTL and CCL, operate at $805 \mathrm{~Hz}$. The CCDTL takes energy to 95 $\mathrm{MeV}$, where the transition to CCL takes place. The bulk of the acceleration takes place in the CCL. The low-energy component of the CCL (95 to $165 \mathrm{MeV}$ ) consists of eight cells per segment, where "segment" refers to a contiguous section of accelerating cavities between two quadrupole focusing magnets. The high-energy component of the CCL (165 Mev to $1 \mathrm{GeV})$ consists of 10 cells per segment. 


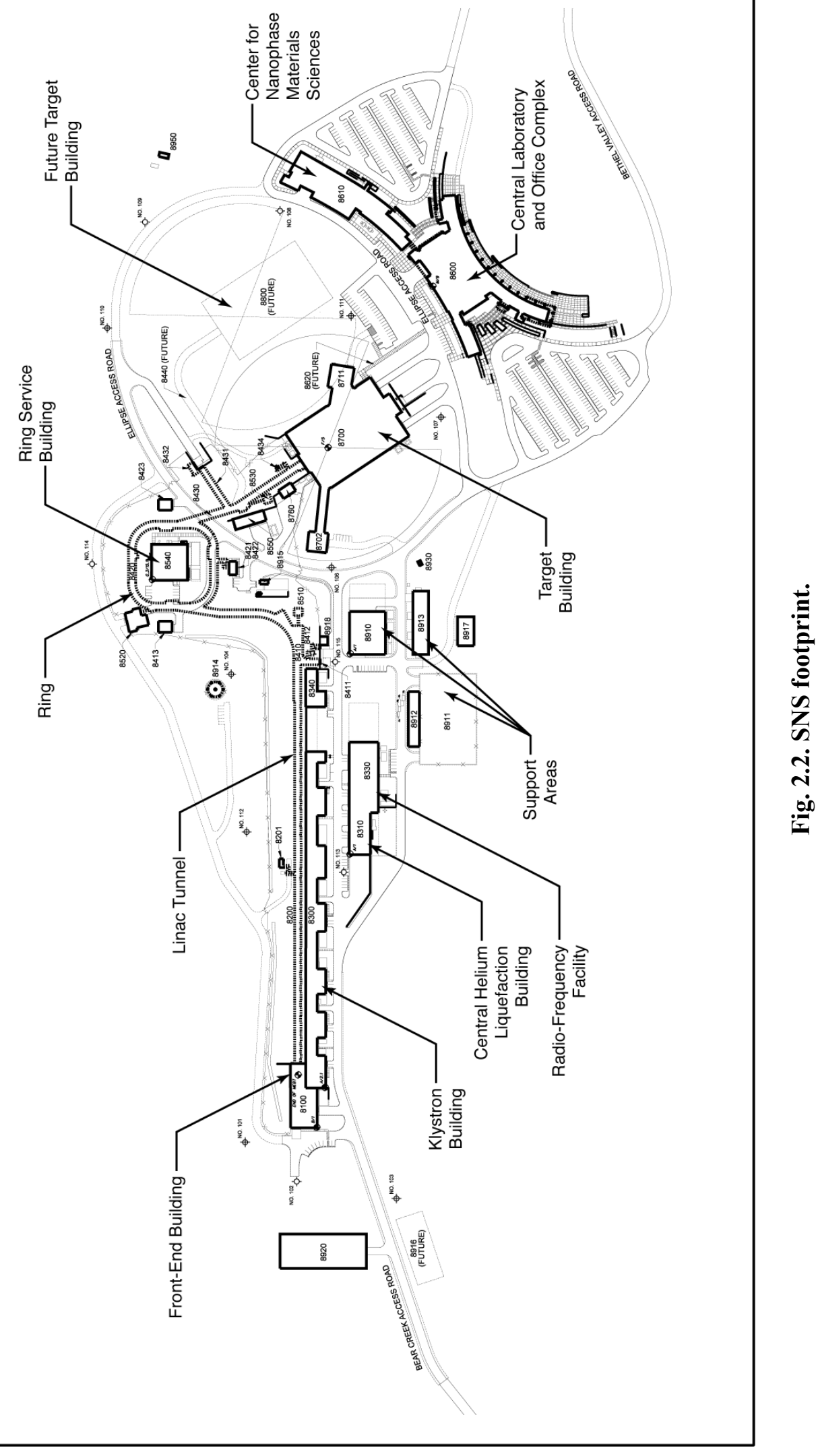


Table 2.1. SNS facilities and distances

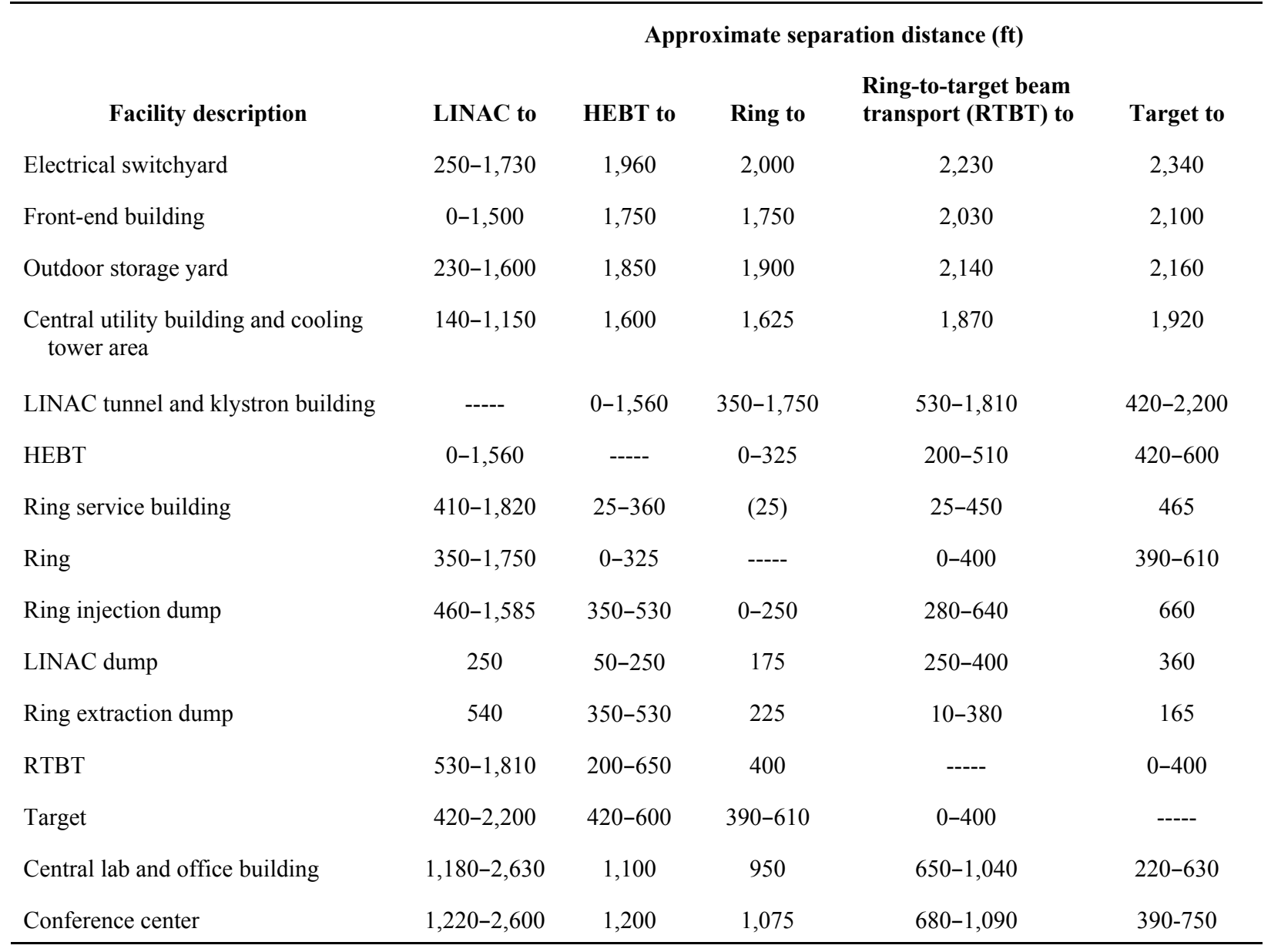

\subsubsection{Ring and Beam Transport Systems}

The SNS consists of three major ring systems: the HEBT system, the accumulator ring itself, and the RTBT system. Three support buildings-the HEBT services and support building, the ring support building in the center of the ring, and the RTBT support building-will house power supplies, monitoring devices, rf equipment, etc., for the major systems. These facilities are shown in Fig. 2.2. The HEBT provides the link between the LINAC and the accumulator ring. The beam coming out of the LINAC is a $1.0-\mathrm{GeV} \mathrm{H}$ ! beam, with a peak current of $28 \mathrm{~mA}$. The total length of the HEBT line will be $192 \mathrm{~m}$, and the total bending angle will be $90 \mathrm{E}$. The line will provide locations for beam scraping of the halo particles (i.e., collimators).

The primary function of the proton accumulator ring is to take a $1-\mathrm{ms}, 1.0-\mathrm{GeV} \mathrm{H}$ ! beam from the LINAC and compress it to a $0.5-\mathrm{Fs}$ pulse by accumulating 1,158 turns in the ring. The final beam will have $2 \mathrm{H} 10^{14}$ protons per pulse, meeting the specifications of a 1-MW design average beam power at a $60-\mathrm{Hz}$ repetition rate. A missing magnet design is used to reduce the dispersion function to zero in the straight sections of the ring.

The RTBT system takes the extracted beam from the ring and transports it to the target. The extraction starts with an eight-module kicker magnet array to deflect the circulating beam, followed by a Lamberston magnet to bend the beam vertically out of the ring (????). A small dipole magnet brings the beam back to a horizontal direction, resulting in a beam height of $\sim 1 \mathrm{ft}$ above the ring beam height. The magnet apertures in this line will be sized to allow for malfunctions of one of the eight extraction kicker 
magnets, protecting the line against excessive beam losses. A beam shape control section will be provided for the final beam shape tuning for the target. Additional focusing control will provide compensation for the window scattering before the target. The total length of the RTBT line will be $180 \mathrm{~m}$, and the total horizontal bend angle will be $15 \mathrm{E}$

\subsubsection{Target Systems}

The target systems primary function is to provide short pulses of low-energy neutrons to neutronscattering instruments. This is achieved through the high-energy spallation reactions from the incoming proton beam from the RTBT and the liquid mercury target. A secondary function is to safely contain the target material in a system that can transport the proton beam power and resulting radiation to a secondary cooling system.

The target module consists of the mercury target vessel, water-cooled shroud surrounding this vessel, and the plug that contains mercury and the water feed and return lines. Target modules are designed to handle a reference beam profile that has a width of $200 \mathrm{~mm}$ and a height of $70 \mathrm{~mm}$. The peak intensity of the beam over this area is \#0.18 A/ $\mathrm{m}^{2}$. For normal operating conditions, the peak temperature of the stainless steel target vessel is maintained at $<200 \mathrm{EC}(392 \mathrm{EF})$. The module extends from the center of the target shielding monolith to the inside of the target cell. Because it is directly in line with the proton beam, it includes passive shielding provisions, which incorporate dog-legs in the piping to prevent generation of excess radiation in the target cell in the event of mercury loss. The modules also include wheels to facilitate retraction into the hot cell. Expectations are that the target module will be replaced twice a year. Because of the effects of interaction with the proton beam, the target module structure will be replaced at least every four operating months.

The target plug is the structure that spans the region from the target module to the flange that interfaces with the process equipment located in the target cell. The target plug contains the feed and return lines for the mercury and water systems and shielding. A vertical offset in the plug is provided to control neutron streaming through the 5-mm clearance gaps between the plug and the surrounding vessel that contains the bulk shielding. The offset also provides shielding in the unlikely event that mercury is lost from the piping while the beam is on. A target transport system is provided to facilitate remote replacement of the target plug within five 8-hour working shifts.

The target process systems include the liquid mercury process equipment and water process systems used to cool the shroud surrounding the mercury vessel. The mercury flow loop used to feed the target and the water flow loop used to cool the shroud surrounding the mercury target are required to transport the power deposited in the target module structures. The transport includes removable shielding. This equipment includes the mercury pump, heat exchanger, mercury storage tanks, valves, etc.

The target station includes four moderators to slow spallation neutrons to energy levels needed in experiments, beam ports in the biological shield, and beam shutters capable of blocking each of these beam ports. The beam ports are large enough to accommodate a range of beam-defining inserts: apertures, guides, collimators, and the associated shielding immediately surrounding the beam. These inserts are used to define the size and shape of the neutron beam required for specific instruments in the experiment systems.

The target station also includes neutron beam shutters, which are designed to accommodate a wide variety of beam-defining inserts. This accommodation is accomplished by providing a large, stepped passage through the shutter to be filled by components provided as part of the experimental instrument. Some instruments will require guides that pass through the shutters, so the shutters must be capable of small rotations about the vertical axis and of vertical and horizontal adjustments necessary to optimize guide alignment. 


\subsubsection{Experiment Facilities}

Experimental facilities include the neutron-scattering instruments located on the neutron beam radiating from the target station. The target station will provide at least 18 neutron beams, and the associated experiment hall is sized to accommodate the neutron-scattering instruments for these beams. Most of the neutron-scattering instruments fit entirely within this experiment hall, but a few long-flightpath instruments will be on beam lines that extend through the walls of the experiment hall. The experiment facilities also include facilities to support operation of the instruments. These support facilities will include offices, shops, and laboratories that are housed in an experiment support building adjacent to the experiment hall.

\subsection{RADIOLOGICAL CONTROLS}

SNS personnel exposed to standard industrial hazards will use the same ORNL support organizations, controls, and mechanisms as other ORNL organizations. Controls for a wide range of hazards and conditions are identified in SNS system requirements documents (SRDs), which also document ORNL's radiological control policies and administrative levels for action. SNS management expectations for radiological protection are documented in SNS management and quality assurance plans.

General rules for training are provided by ORNL directives for training and qualifications. All applicable SNS personnel will receive appropriate training on the SRDs.

SNS is committed to the Integrated Safety Management System precept of continuous improvement. SNS intends to continue to improve its management programs, including those for ES\&H, and to continually search for the most meaningful metrics and indicators for feedback.

SNS management has developed mechanisms to involve the following three committees in radiation safety review activities: the Radiation Safety Committee, ALARA Committee, and the Accelerator Safety Review Committee. Effective interaction and communication, including periodic reviews, with these committees will help ensure that the SNS is designed, built, and operated according to the highest radiation safety standards.

\subsubsection{Radiation Safety Committee}

The Radiation Safety Committee was charged with the responsibility for resolving radiation safety issues as they arise during day-to-day design. The chairman of the committee reports to the SNS administrative director. Committee membership is listed in Table 2.2. Note that membership will change as the project evolves.

Table 2.2. Radiation Safety Committee membership

\begin{tabular}{ll}
\hline \multicolumn{1}{c}{ Name } & \multicolumn{1}{c}{ Title } \\
Frank Kornegay & Chairman \\
Paul Wright & SNS Personnel Protection System (PPS) \\
Jonathan Haire & SNS radiological support \\
Ken Reece & SNS Accelerator Division \\
Don Gregory & ORNL Operational Safety Services Division (OSSD) \\
\hline
\end{tabular}




\subsubsection{ALARA Committee}

The SNS project will have an ALARA committee, which will focus exclusively on radiation dose reduction and environmental issues. This committee is currently part of the SNS Radiation Safety Committee but will become separate during Title II design. Thus, the committee will be involved early in the facility design process and will be consulted routinely regarding design and operational maintenance issues. The ALARA committee will perform and documents ALARA reviews of the SNS facilities at appropriate design stages.

\subsubsection{ORNL Accelerator Safety Review Committee}

The SNS project is committed to close cooperation with the Accelerator Safety Review Committee (ASRC), the standing committee that reviews accelerator safety at ORNL, to ensure that the SNS is designed, built, and operated to the highest safety standards. The ASRC conducted an accelerator safety review of the SNS in April 1998, near the end of the conceptual design phase of the project. An information meeting was held in May 1999.

\subsubsection{ORNL Radiation Protection Involvement}

The OSSD at ORNL has been supporting the SNS project since the conceptual design stage. Subject matter experts from OSSD have been providing radiological control advice and have been participating in the radiological design review of the project.

\subsection{REFERENCES}

Boyle, J. W., et al. November 1982. Environmental Analysis of the Operation of Oak Ridge National Laboratory (X-10 Site), ORNL-5870, Union Carbide Corporation, Oak Ridge Natl. Lab.

Fitzpatrick, F. C. December 1982. Oak Ridge National Laboratory Site Data for Safety Analysis Reports, ORNL/ENG/TM-19, Union Carbide Corporation, Oak Ridge Natl. Lab.

Lockheed Martin Energy Research, Inc (LMER). February 2000. Spallation Neutron Source Preliminary Safety Analysis Report, SNS 102030102-ES0001-R00, Lockheed Martin Energy Research, Inc., Spallation Neutron Source, Oak Ridge, Tenn.

Moore, G. K. September 1989. Groundwater Parameters and Flow Systems Near Oak Ridge National Laboratory, ORNL/TM-11386, Environmental Sciences Division Publication No. 3403, Martin Marietta Energy Systems, Inc., Oak Ridge Natl. Lab. 


\section{RADIATION PROTECTION DESIGN CRITERIA AND RADIATION LEVEL LIMITS}

ALARA principles have been emphasized during the early design stages of the SNS to minimize radiation exposures of workers and the general public. Radiation level limits, selection of areas, and bases for shielding requirements had been documented in the NSNS Shielding Policy (LMER 1997). The ALARA design criteria were considered in the SNS Design Manual (August 1998) and the SRD (LMER 1999) for various engineering disciplines. Evaluation of the ALARA design features against SNS design criteria is discussed in Section 5. The following two sections summarize the radiation level limits and shielding design goals contained in the NSNS Shielding Policy (LMER 1997).

\subsection{SNS GENERAL SITE AREA}

Radiation levels outside the SNS controlled area (see Figs. 3.1 and 3.2) will be sufficiently low such that active measures are not necessary to control possible incidental intrusions by members of the general public. No fence is needed to control access to the large area that extends out to Bethel Valley or Bear Creek Roads. Warning signs near Bethel Valley Road will discourage casual use of the SNS access road. An existing warning sign across Bear Creek Road, west of the SNS site, discourages approach by the public.

A dose limit of $10 \mathrm{mrem} /$ year was set for the locations of the warning signs (see first paragraph), or along Bethel Valley or Bear Creek Roads, considering all sources of external radiation from SNS operations (per year of operation).

\subsection{POSTED AREAS}

A fence will limit access to the controlled area and will surround all buildings with a non-negligible radiation hazard. In some cases, the outer wall of a building may serve as part of the fence. Note that some buildings (e.g., the administration building) will be the outside of the controlled area but well within the site boundary. Ingress and egress through the fenced area will be by card key. Radiation areas within the controlled area are defined according to the radiation level inside each area: Radiation Area, High Radiation Area, and Very High Radiation Area. Title 10 of the Code of Federal Regulations, Section 835 (10 CFR 835) provides requirements for posting of and controlling access to each type of radiation area. (Note that the area designation may be reduced after accelerator shutdown, as provided by appropriate radiological protection procedures.)

For design considerations, the allowable radiation levels within continuously occupied parts of the controlled area will be such that the dose to the maximally exposed worker will be $<500 \mathrm{mrem} /$ year. Allowable radiation levels within the controlled area must also be consistent with very low dose levels for visitors: $100 \mathrm{mrem} / \mathrm{year}$ for nonradiological workers and $50 \mathrm{mrem} / \mathrm{year}$ for members of the public without dosimeters. Shielding design requirements for parts of the facility that do not have occupancy time limits and/or special access controls (e.g., higher levels of card key and other control mechanisms and/or requirements) are a dose rate of $<0.25 \mathrm{mrem} / \mathrm{h}$ at accessible exterior surface(s) of shielding with the facility operating at its maximum design level. Shielding design requirements for parts of the facility that do have time occupancy limits and/or special access and rad-worker training controls might allow radiation dose rates above the $0.125 \mathrm{mrem} / \mathrm{h}$ design limit. Additional design requirements include consideration of ALARA principles and ensuring that worker exposure levels are $<1000 \mathrm{mrem} / \mathrm{year}$ for areas that are not continuously occupied. 


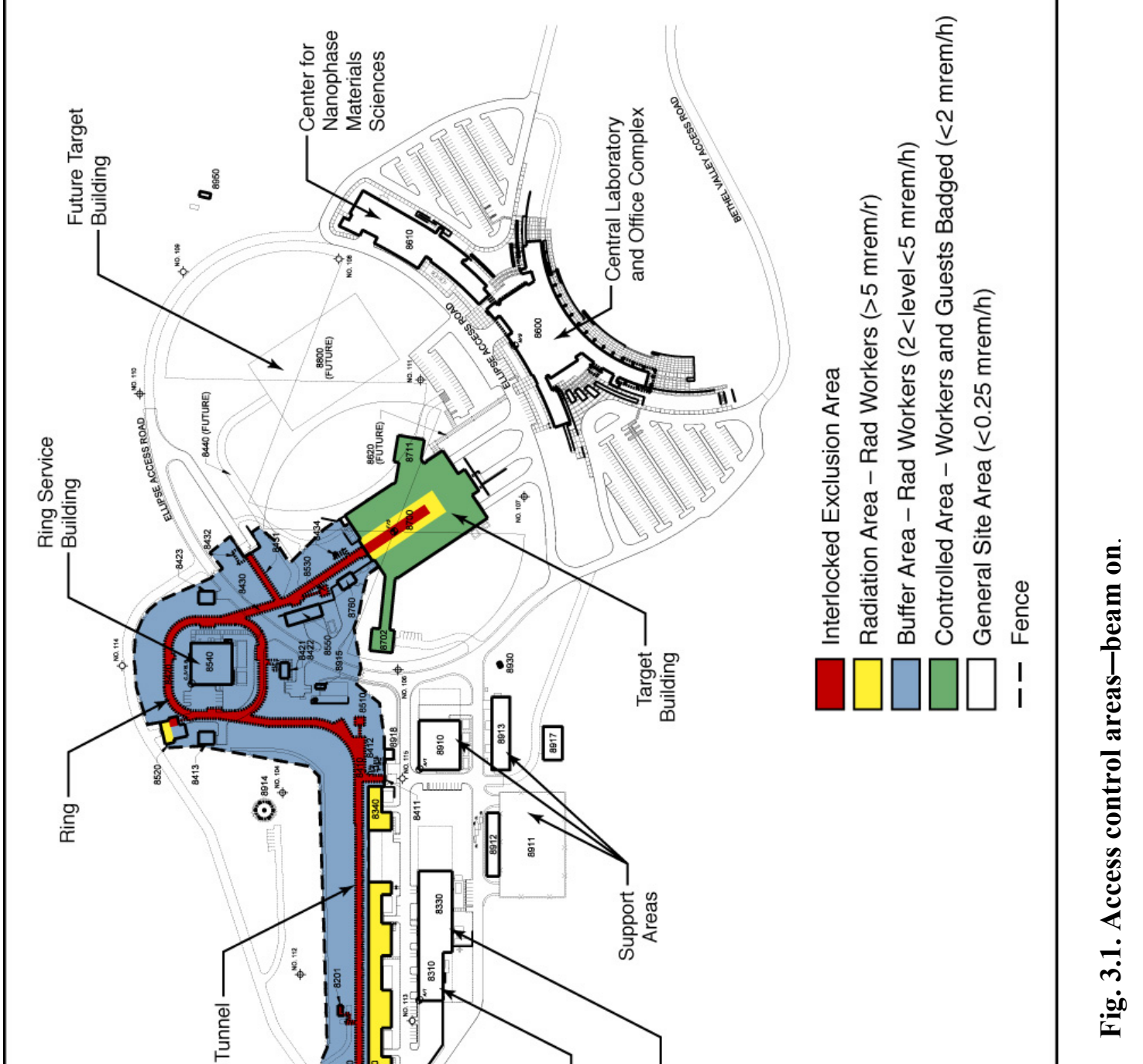




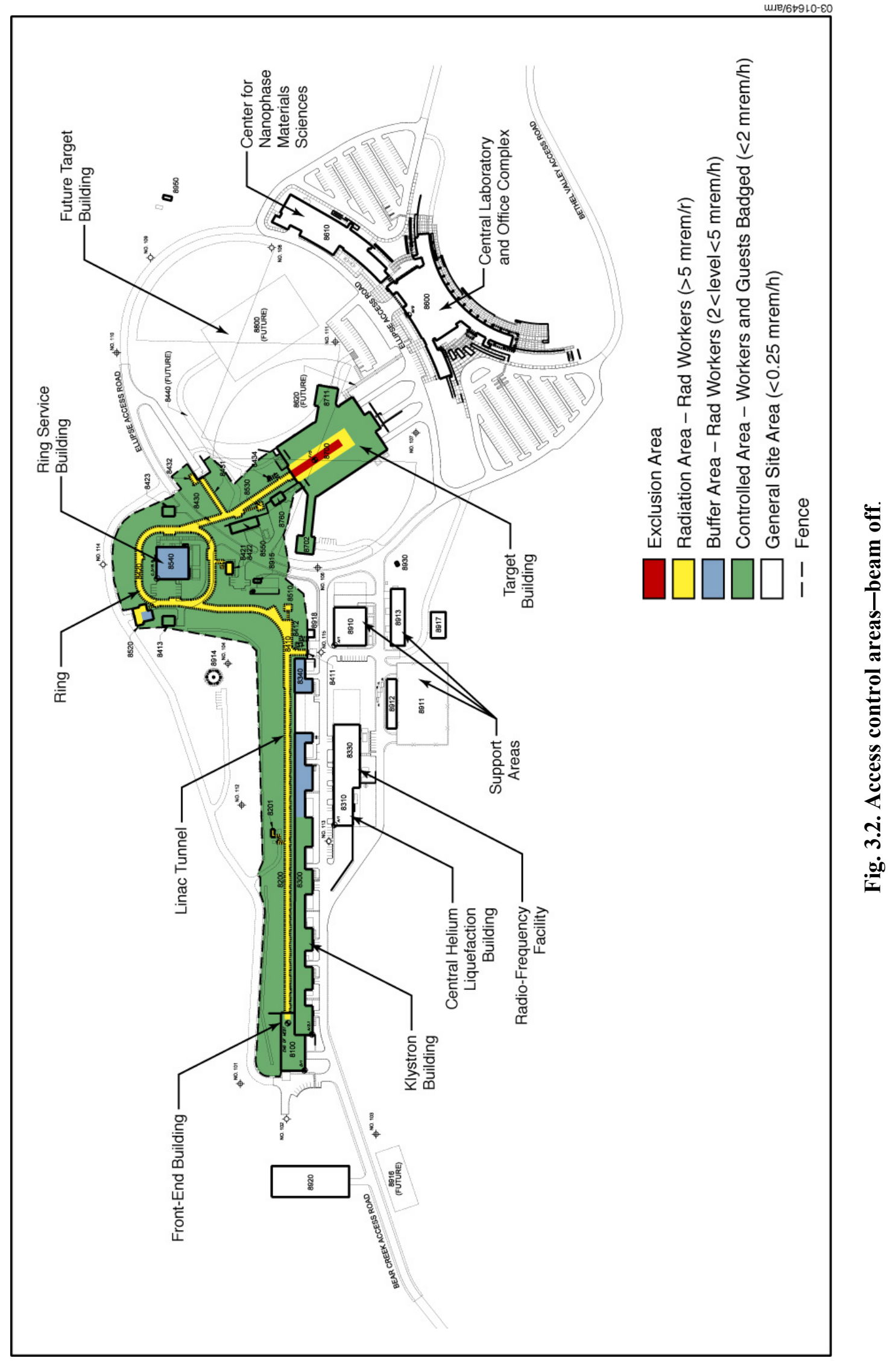


Shielding design thickness must provide for passive personnel safety assurance in the event of proton beam control accidents. The integrated radiation dose at any accessible point in the controlled area outside the accelerator shielding shall not exceed 25 rem as a result of the maximum credible beam control accident. The corresponding requirement for any member of the public outside the controlled area for the same event is a maximum of $1 \mathrm{rem}$. These quantitative goals are taken from the U.S. Department of Energy (DOE) guidance document corresponding to DOE Order 5480.25, the order that has been superceded by the current accelerator safety order, DOE O 420.2A, Safety of Accelerator Facilities. (Note that similar guidelines may be found in Environmental Protection Agency Manual of Protective Action Guides and Protective Actions for Nuclear Incidents, 400-R-92-001, and in DOE G151. 1-1, Volume 2, Hazardous Survey and Hazards Assessments, Appendix B.) These guidelines and limits are summarized in Tables 3.1 and 3.2.

Contamination and/or airborne radioactivity areas will be defined within specific areas inside the controlled area on an as-needed basis. Access to and surveillance of contamination or radiation areas will be controlled by appropriate procedures that implement the requirements of 10 CFR 835. Contamination and airborne radioactivity control is beyond the scope of this document.

Building layout and design must be consistent with ALARA principles, for example, auxiliary facilities such as labs, break rooms, and bathrooms should, where possible, be situated in locations with very low or negligible radiation levels.

\subsection{REFERENCES}

Lockheed Martin Energy Research, Inc. (LMER). May 1997. NSNS Shielding Policy, NSNS/97-9, Lockheed Martin Energy Research, Inc., National Spallation Neutron Source, Oak Ridge, Tenn.

Lockheed Martin Energy Research, Inc. (LMER). September 1999. System Requirements Document for the Spallation Neutron Source Ring and Transport Line Conventional Facilities, SNS 108030500SR0001-R00, Lockheed Martin Energy Research, Inc., Spallation Neutron Source, Oak Ridge, Tenn. 


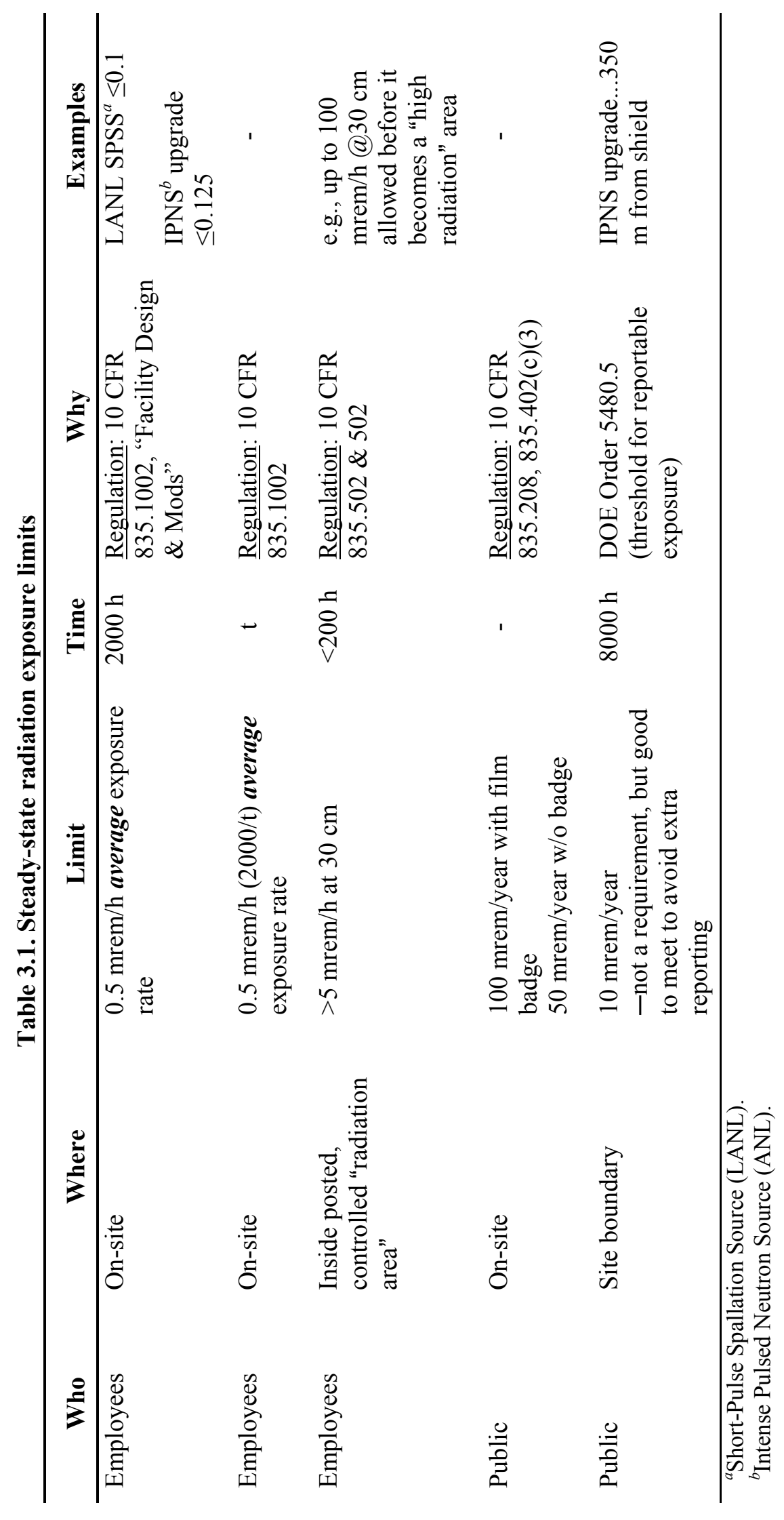




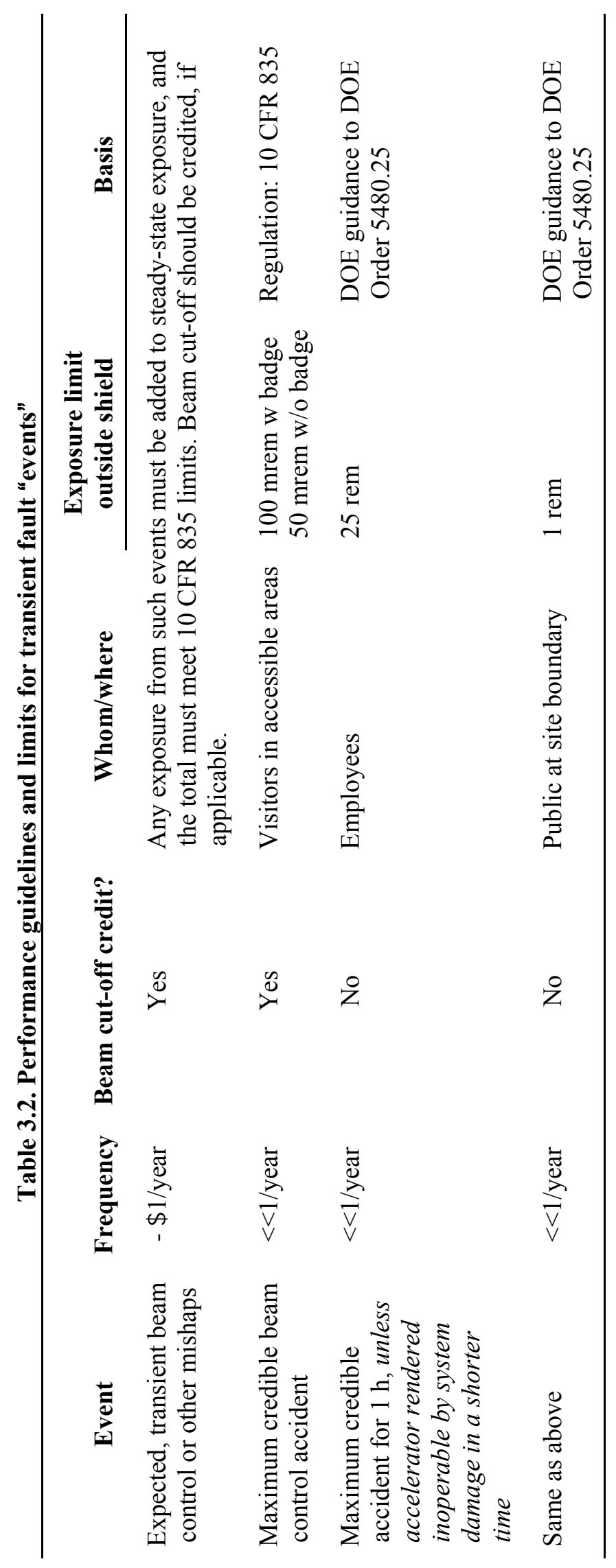




\section{PRINCIPAL RADIATION HAZARDS}

This section summarizes radiation dose levels at various key locations. The following are described: the source of radiation, general radiation background (i.e., from beam vacuum chamber walls), radiation dose near (quadrupole) magnets, dose from collimators, and the dose near beam dumps. Also discussed are the time dependence of radiation dose following machine shutdown and induced radioactivity in ventilation air and cooling water.

\subsection{IDENTIFICATION OF HAZARDS}

The principal radiation hazards associated with the SNS accumulator ring result from operation with a high proton beam flux. These hazards include the following:

- direct exposure to the primary proton beam,

- secondary radiation created by primary beam losses during normal operation or during episodes of abnormal beam losses,

- residual radiation induced in machine components and in the beam dump during normal operation or during episodes of abnormal losses,

- activation of cooling water caused by secondary radiation,

- activation of the tunnel enclosure and the soil in the earth shielding surrounding the tunnel because of secondary radiation, and

- activation of air in the tunnel because of secondary radiation.

\subsection{SOURCE TERM AND EARTH BERM SHIELDING}

The SNS design requirement is $1 \mathrm{~W} / \mathrm{m}$ of uncontrolled beam loss. This requirement corresponds to a fractional beam loss of $-10^{-4} / \mathrm{m}$ for the $220-\mathrm{m}$ circumference of the ring. The ring and transfer lines have general external earth berm shielding of $18 \mathrm{in}$. of concrete in the tunnel walls and $17 \mathrm{ft}$ of earth berm outside the walls. The resulting radiation dose at the surface of the earth berm is $0.085 \mathrm{mrem} / \mathrm{h}$. The radiation dose for a maximum credible beam loss event $(100 \%$ beam loss for a short, $<1 \mathrm{sec}$, period of time) is $28 \mathrm{rem} / \mathrm{h}$.

In addition to the general earth berm, local shielding will be placed inside the tunnel near locations of possible higher fractional beam losses. Three mobile local shields are being designed to fit around the beam line to provide acceptable dose levels to operating staff should localized higher beam losses occur.

\subsection{INDUCED RADIOACTIVITY}

When a high-energy proton interacts with nuclei of accelerator components, neutrons, protons, pions, and other nuclear fragments are emitted, converting the struck nucleus to that of a different isotope, which is likely radioactive. Some of the emitted secondary particles may have sufficient energy to cause further activation by spallation reactions or by being captured by nearby nuclei, resulting in the production of additional radioactive isotopes. Although the overall quantity of radioactivity induced in the accelerator depends on the primary beam loss, the probability of producing a particular isotope will depend on the composition of the material struck, the spectrum of secondary particles produced, and the interaction cross section of the isotope concerned. The amount of a radioactive isotope present at any given time will also depend on the isotope half-life, how long the accelerator has been operating, and the time the radioisotope has had to decay since accelerator operation stopped. Hence, the complexity of the processes governing the amount of radioactivity in the accelerator at any one time makes it difficult to quantify the radioactivity in any detail. However, it is necessary to consider the planned beam losses and estimate the 
magnitude of radiation hazard produced by the induced activity. Induced radioactivity is superimposed on activity because of beam loss during accelerator operation and is residual radioactivity that must be considered after beam shutdown during accelerator maintenance.

\subsubsection{Residual Radiation in Machine Components}

Ludewig (1999) gives a detailed description of induced radiation in the HEBT, ring, and RTBT tunnels.

\subsubsection{Vacuum Chamber Wall}

The vacuum chamber walls of the SNS are subject to an average uncontrolled proton loss of $1 \mathrm{~W} / \mathrm{m}$ under normal operating conditions. These lost protons cause spallation reactions in the chamber walls, resulting in residual gamma radiation following machine shutdown. This radiation is considered background radiation in the HEBT, ring, and RTBT tunnels.

At an energy of $1 \mathrm{GeV}$ and a chamber diameter of $20 \mathrm{~cm}$, the proton flux implied from a $1-\mathrm{W} / \mathrm{m}$ beam loss is $9.89 \mathrm{H} 10^{5} \mathrm{p} / \mathrm{cm}^{2}$-s. The vacuum chamber is a cylindrical structure with an inner diameter of $20 \mathrm{~cm}$ and a wall thickness of $1 \mathrm{~cm}$. The chamber is constructed of type 304 stainless steel $(9 \% \mathrm{Ni}, 19 \% \mathrm{Cr}, 72 \%$ $\mathrm{Fe}$ ). The resulting radiation dose following 180 days of operation is shown in Table 4.2. The data show that the dose drops off rapidly with distance and that it falls within the $\mathrm{mrem} /$ hour range beyond $-50 \mathrm{~cm}$.

Table 4.1. Dose as a function of distance from the HEBT, ring, and RTBT vacuum chamber following 180 days of operation

\begin{tabular}{cc}
\hline Distance & Dose (rem/h) \\
$10 \mathrm{~cm}($ surface $)$ & 11.1 \\
$41 \mathrm{~cm}(-1 \mathrm{ft})$ & $5.41 \mathrm{H} 10^{-2}$ \\
$110 \mathrm{~cm}$ & $6.64 \mathrm{H}_{10}^{-3}$ \\
\hline
\end{tabular}

\subsubsection{Quadrupole Magnets}

A more likely situation than an isolated vacuum chamber is a vacuum chamber connected to an accelerator component. Such a situation is shown in Fig. 4.1, where beam protons move from left to right. Protons scatter out of the vacuum chamber and interact with adjacent magnets, activating them and further adding to tunnel background radiation. Gamma sources were determined for volumes of interest within the chamber walls and adjacent magnet structure. The estimated doses shown in the figure are based on a beam loss rate of $1 \mathrm{~W} / \mathrm{m}$ of wall length with the accelerator operating for 180 days.

Figure 4.1 shows that for the radial variation furthest from the magnet (extreme right-hand side), the dose at $50 \mathrm{~cm}$ is equivalent to the dose at $41 \mathrm{~cm}$ for the isolated chamber case $-57 \mathrm{vs} 54 \mathrm{mrem} / \mathrm{h}$. Beyond $50 \mathrm{~cm}$, the radiation dose drop occurs inverse to the radius square. Note that the magnet structure is largely self-shielding and that the contribution to the tunnel dose (e.g., at $100 \mathrm{~cm}$ radius) is not as large as might be thought.

\subsubsection{Collimators}

Collimators intentionally capture beam halo protons, causing spallation product generation in the collimator structure. Figure 4.2 is a schematic of collimator components. The bulk of the radiation from these products will be contained by the collimator structure. However, a fraction of the radiation will leak out of the collimator, adding to the background gamma radiation level. 
Collimators are located in all the transfer line tunnels and the ring tunnel. Two collimators are located at the end of the LINAC in the HEBT tunnel, and one is located about halfway around the HEBT tunnel. In the ring, three collimators are located in the straight section between injection and ejection straights. The RTBT has two collimators located about halfway along the length of the tunnel and one at the end of the tunnel just before the target. The collimator in front of the target acts as a shield for the accelerator from back-streaming radiation from the target.

Dose calculations have been made (Ludewig 1999) for a proton beam entering the front of a collimator and causing spallation reactions inside the collimator body. The shape of the halo beam was assumed to be cylindrical with its highest intensity closest to the inner radius $(2.5 \mathrm{~cm})$ and dropping off in a step-wise fashion to zero at the outer source radius $(4.5 \mathrm{~cm})$. The estimate of proton current was based on a beam loss fraction of $10^{-3}$ for a machine operating at $2 \mathrm{MW}$. This implies a current of $2.06 \mathrm{H} 10^{-6}$ amps and a machine current of $1.24 \mathrm{H} 10^{13} \mathrm{p} / \mathrm{s}$. The operating period of the machine was assumed to be 180 days. A gamma source was determined for 27 incremental volumes within the collimator. The source corresponding to water-filled volumes was omitted because it is assumed that the collimator will be drained during maintenance.

Under normal operating conditions, the collimator will be shielded by $65 \mathrm{~cm}$ of iron in the axial directions (both forward and backward) and by $20 \mathrm{~cm}$ of iron in the radial direction. This configuration is shown in Fig. 4.3. Also shown in the figure is the position of a movable shield placed in the backward direction to aid in attenuating the relatively high doses along the beam line. The movable shield could be used in the event of maintenance work, which might be necessary for a component downstream of the collimator. An 18.5-in.- thick layer of lead is assumed to be representative of the movable shield. To compare doses with and without the movable shield being present, two calculations were carried out and the dose determined at specific axial and radial positions. These locations are shown numerically on Fig. 4.3, together with radial and axial distances. A comparison of the results is shown in Table 4.3.

\subsubsection{Beam Dumps}

Beam directed into the injection dump has been estimated to be as much as $10 \%$ of beam flux, or $1.25 \mathrm{H} 10^{15} \mathrm{p} / \mathrm{s}$ at $1 \mathrm{Gev}$. The ring injection dump is copper and is sized at $200 \mathrm{~kW}$, or $10 \%$ of beam, to handle this loss. This loss gives a peak radiation level of $1.0 \mathrm{mrem} / \mathrm{h}$ at the surface of the floor above the dump. The injection dump is shielded internally with $144 \mathrm{in.} \mathrm{of} \mathrm{steel.} \mathrm{The} \mathrm{radiation} \mathrm{dose} \mathrm{at} \mathrm{the} \mathrm{surface} \mathrm{of}$ the floor above the beam stop is $1 \mathrm{mrem} / \mathrm{h}$, assuming $10^{15} \mathrm{p} / \mathrm{s}$ for the $200-\mathrm{kW}$ beam injection dump and $374 \mathrm{~cm}$ (147 in.) of steel. The SNS design is for $144 \mathrm{in}$. of steel and $2 \mathrm{ft}$ of concrete above the steel shield. This calculation does not consider the further reduction in dose because of the concrete.

The 33-kW LINAC and extraction beam dumps have the same dimensions of steel shielding as does the $200-\mathrm{kW}$ injection beam dump because the shield block dimensions are $52 \mathrm{H} 52 \mathrm{H} 26$ in. The $33-\mathrm{kW}$ beam stops are made of steel; therefore, they have correspondingly lower radiation dose levels.

Beam dumps become highly radioactive, and a beam of radiation will shine backward through the beam line into the ring tunnel. This backward shine could be a problem during maintenance, and consideration should be given to providing a shutter, or beam plug, to reduce this radiation to workers in the ring tunnel. All three beam stops share this feature. 

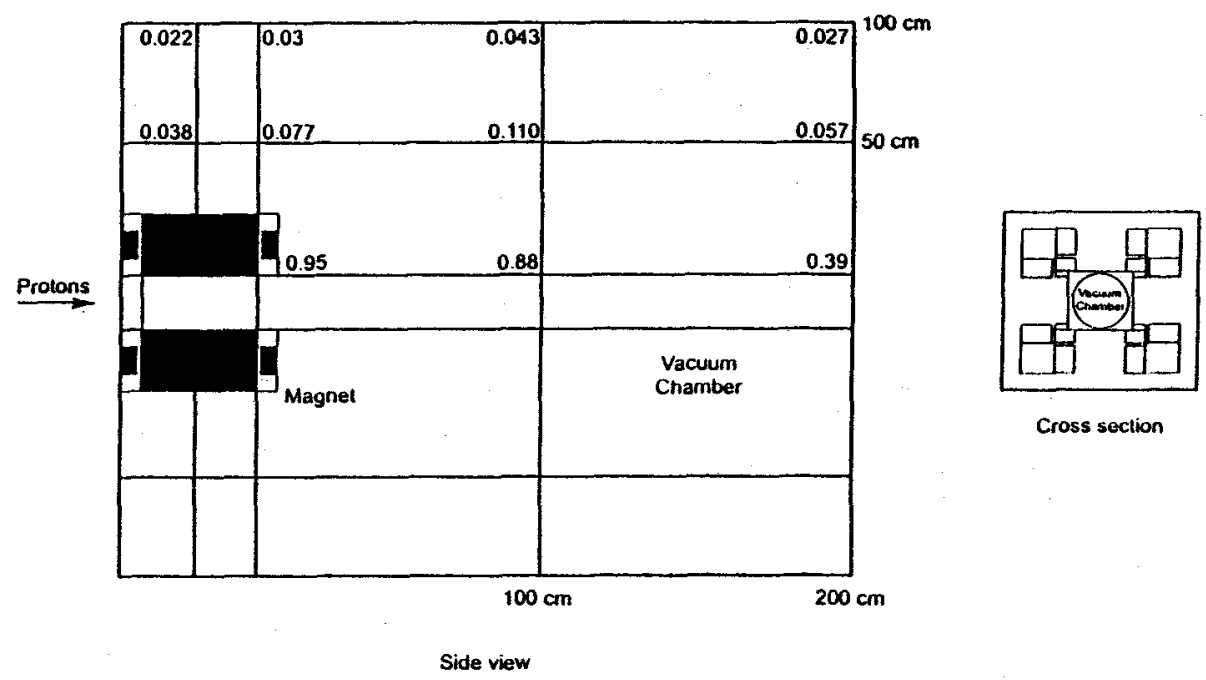

Fig. 4.1. Quadrupole magnet with 2-m-long vacuum chamber (dose in rem/hour).

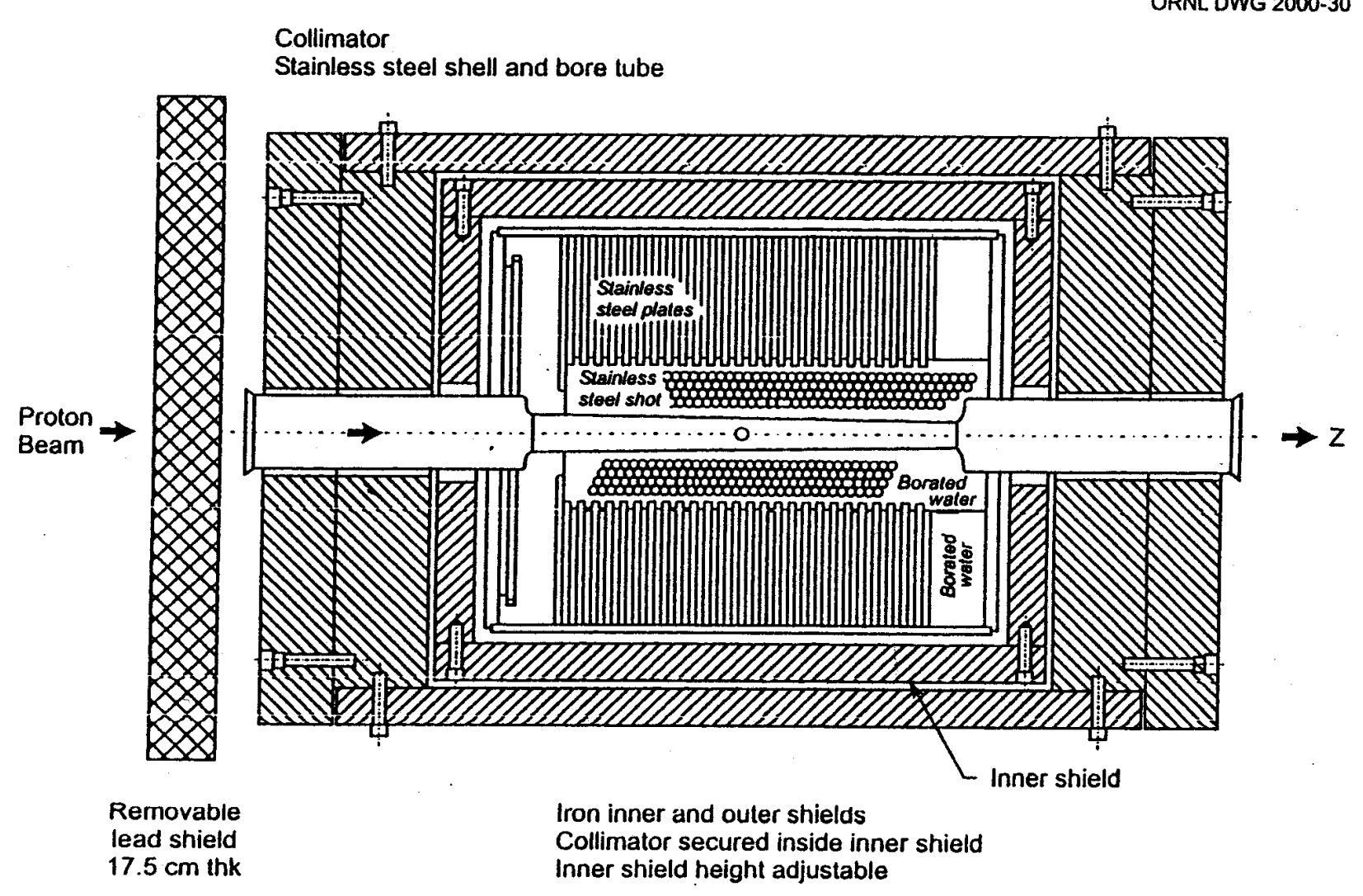

Fig. 4.2. Schematic of collimator components (horizontal section). 


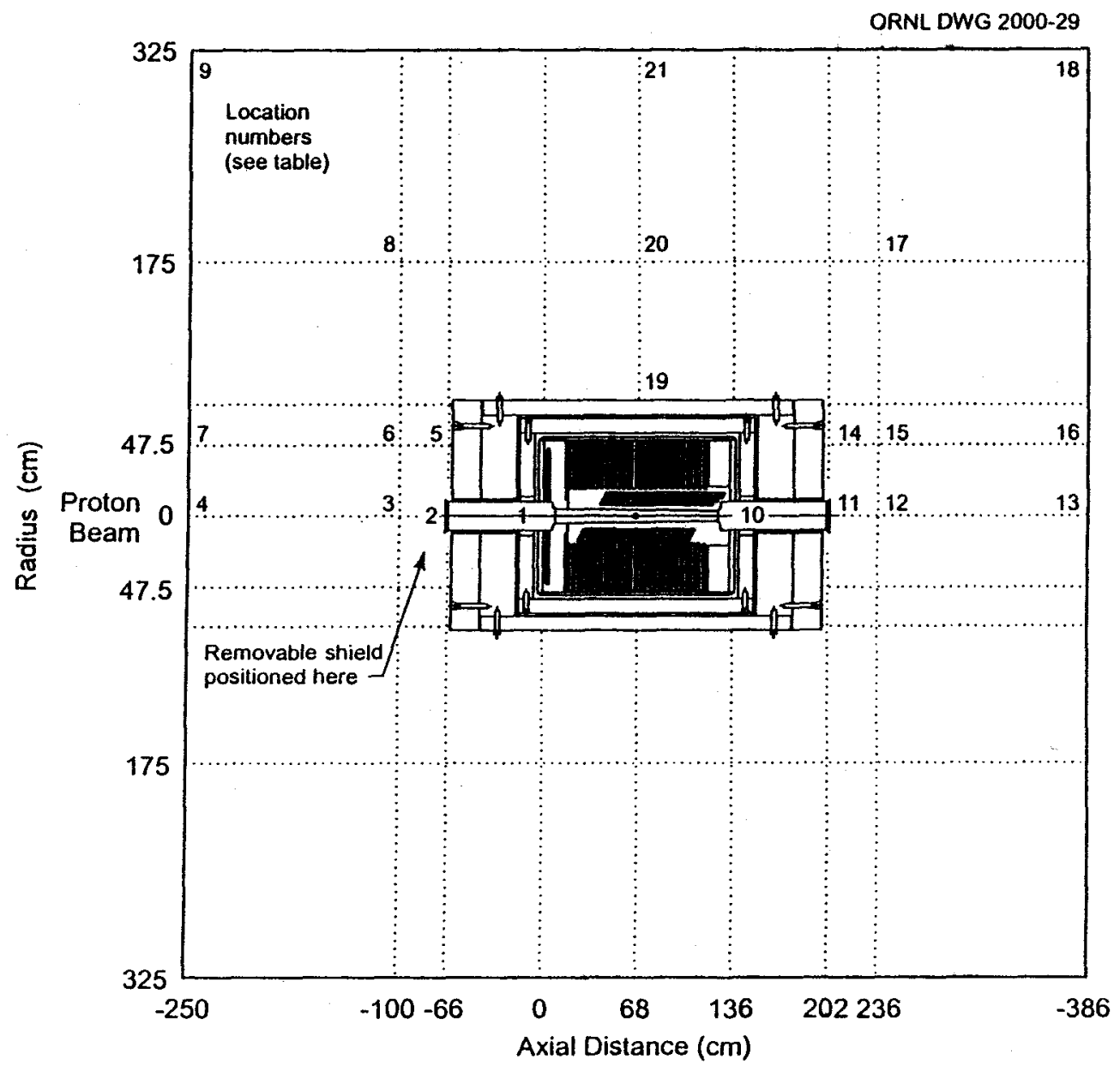

Fig. 4.3. Location numbers around shielded collimator.

\subsubsection{Time Dependence of Dose Following Machine Shutdown}

The time dependence of the aforementioned dose levels can be estimated by determining the gamma spectrum changes with time as the various radionuclides of interest decay. This change in gamma spectrum involves a reduction in the absolute magnitude of the source (photons/s) and a change in the energy distribution of the spectrum since the various nuclides that make up the spectrum decay at different rates. For irradiated stainless steel, the reduction in magnitude is more important than the change in energy distribution. This suggests that for the collimator, magnet, and vacuum chamber calculations described previously, the reduction in dose at any location can be estimated by reducing the dose determined at shutdown by the fractional change in gamma intensity. The reduction in gamma intensity is shown in Table 4.4.

The previous estimate indicates that after a month the dose will have been reduced to - $15 \%$ of the value at shutdown. The drop-off is relatively rapid in the first day and then slows. 
Table 4.2. Doses for shielded collimator (standard configuration)

with and without movable shield

\begin{tabular}{|c|c|c|}
\hline \multirow[b]{2}{*}{ Location no. shown in Fig. 4.3} & \multicolumn{2}{|c|}{ Dose (rem/h) } \\
\hline & No movable shield & With movable shield \\
\hline 1 & 9,581 & 9,586 \\
\hline 2 & 77 & --- \\
\hline 3 & 29 & $2.0 \mathrm{H} 10^{-3 a}$ \\
\hline 4 & 4 & $1.5 \mathrm{H} 10^{-4 a}$ \\
\hline 5 & $2.2 \mathrm{H} 10^{-3}$ & -- \\
\hline 6 & 0.13 & $4.5 \mathrm{H} 10^{-6 a}$ \\
\hline 7 & 1.1 & $9.6 \mathrm{H}^{1} 0^{-6 a}$ \\
\hline 8 & $2.1 \mathrm{H} 10^{-3}$ & $3.5 \mathrm{H} 10^{-4 a}$ \\
\hline 9 & $1.8 \mathrm{H} 10^{-3}$ & $9.1 \mathrm{H} 10^{-5 a}$ \\
\hline 10 & 105 & 106 \\
\hline 11 & 1.4 & 1.4 \\
\hline 12 & 0.7 & 0.7 \\
\hline 13 & 0.12 & 0.12 \\
\hline 14 & $3.2 \mathrm{H} 10^{-5}$ & $7.1 \mathrm{H} 10^{-6}$ \\
\hline 15 & $1.1 \mathrm{H} 10^{-3}$ & $1.1 \mathrm{H} 10^{-3}$ \\
\hline 16 & $7.9 \mathrm{H}_{1} 0^{-3}$ & $8.6 \mathrm{H} 10^{-3}$ \\
\hline 17 & $5.7 \mathrm{H}_{10} 0^{-5}$ & $5.7 \mathrm{H} 10^{-5}$ \\
\hline 18 & $4.2 \mathrm{H} 10^{-5}$ & $5.1 \mathrm{H} 10^{-5}$ \\
\hline 19 & $8.0 \mathrm{H} 10^{-5}$ & $5.6 \mathrm{H} 10^{-5}$ \\
\hline 20 & $1.4 \mathrm{H}_{10} 0^{-3}$ & $1.4 \mathrm{H}_{10}^{-3}$ \\
\hline 21 & $9.0 \mathrm{H} 10^{-4}$ & $9.5 \mathrm{H}_{10} 0^{-4}$ \\
\hline
\end{tabular}

${ }^{a}$ Behind movable shield. 
Table 4.3. Reduction in gamma intensity (and dose) with time following shutdown

\begin{tabular}{lccccc}
\hline Time since shutdown & 0 & $1 \mathrm{~h}$ & $1 \mathrm{~d}$ & $7 \mathrm{~d}$ & $30 \mathrm{~d}$ \\
Fractional change & 1.0 & ---- & 0.35 & 0.22 & 0.14 \\
\hline
\end{tabular}

\subsubsection{Induced Activity in Cooling and Fire Protection Water}

Dose levels referenced this section are extrapolated from the advanced gradient synchrotron (AGS) Booster Final Safety Analysis Report (FSAR).

Radioactivity is also produced directly in the closed cooling water system. Indications are that ${ }^{7} \mathrm{Be}$ and ${ }^{3} \mathrm{H}$ are the two long-lived radionuclides that will be produced. Estimates indicate that $-50 \mathrm{mCi}$ of ${ }^{7} \mathrm{Be}$ and $10 \mathrm{mCi}$ of ${ }^{3} \mathrm{H}$ will be produced annually for a total volume of water in the cooling system of $5 \mathrm{H} 10^{5}$ $\mathrm{cm}^{3}$. For ${ }^{3} \mathrm{H}$ and ${ }^{7} \mathrm{Be}$, the concentrations at the end of an annual running period are $2 \mathrm{H} 10^{-2} \mathrm{uCi} / \mathrm{cm}^{3}$ and 1 $\mathrm{H} 10^{-1} \mathrm{uCi} / \mathrm{cm}^{3}$ respectively. Both these concentrations are $>5$ times the DOE Derived Concentration Guides. Radiation monitors in the sanitary waste system will receive ring effluent in the event of an inadvertent release. These monitors are designed to divert radioactive water away from the sewage treatment plants and filter beds and to a lined holdup pond for additional sampling and treatment, instead of direct discharge of the activity. In addition to direct activation of water, slight amounts of radioactivity, which have been induced in the magnets, will be picked up in the cooling water. For example, microcurie amounts of radionuclides such as ${ }^{54} \mathrm{Mn},{ }^{22} \mathrm{Na}$, and ${ }^{65} \mathrm{Zn}$ are expected.

Cooling water is in a closed, recirculated system. The SNS practice will be to monitor closed system or "contact" cooling water before discharge. Additionally, the metals content is monitored in both contact and "secondary" cooling waters. Secondary waters from cooling towers are discharged into recharge basins if the metals content is not greater than permitted. Because these waters do not get activated, radioactivity is not discharged to the recharge basin.

Contact cooling water will contain small amounts of short-lived radioactive gases, ${ }^{15} \mathrm{O}$ and ${ }^{13} \mathrm{~N}$. The external radiation hazard from circulating these gases with cooling water is momentary, lasting 5 to 10 minutes after shutdown of the beam. At maximum study intensities on the beam dump, equilibrium levels shortly after the onset of beam would be as high as $500 \mathrm{mrem} / \mathrm{h}$ at $30 \mathrm{~cm}$ from cooling water piping. Therefore, beam dump cooling water is circulated only inside the ring and LINAC enclosure, allowing a significant decay time to elapse before personnel would be exposed to external radiation from this source.

It is estimated that the production rate of radioactivity in the 4-in.-diam pipe for fire protection water is a factor of - 4 less than the magnet cooling water. Sampling of the fire protection water is necessary to determine whether any administrative controls are necessary, such as periodic drainage of the system to limit buildup.

Given the production of radioactivity in the fire protection water in the standing wet pipe system, the ${ }^{3} \mathrm{H}$ and ${ }^{7} \mathrm{Be}$ concentrations at the end of an annual running period will be $-1 \mathrm{H} 10^{-4}-\mathrm{Ci} / \mathrm{cm}^{3}$ and $6 \mathrm{H}$ $10^{-4} \mathrm{uCi} / \mathrm{cm}^{3}$, respectively. These concentrations are above the set point of the sanitary waste radiation monitors, which is $1.3 \mathrm{H1} 0^{-4} \mathrm{pCi} / \mathrm{cm}^{3}$. Therefore, if this contaminated water were released during a fire, the water would be held up before its release. The transit time of water from the ring to the diversion pump is about 1 hour, allowing time for notification of a discharge from the sprinkler system.

\subsubsection{Induced Activity in Air}

Dose levels in this section are extrapolated from the AGS Booster FSAR.

The radionuclides listed in Table 4.1 are produced in the air within the tunnel and assume a total

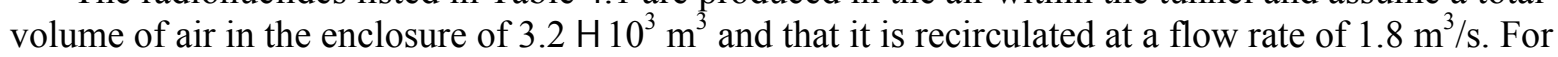
energy conservation during accelerator operation, the air is not normally exhausted, but recirculated, which allows for decay of short-lived ${ }^{11} \mathrm{C},{ }^{13} \mathrm{~N}$, and ${ }^{15} \mathrm{O}$. However, for purposes of this study only, it is assumed that the air is completely exhausted, which would be against operating procedure. This gives a 
maximum bounded estimate of potential environmental release. The release point is from a vent mounted on top of the tunnel at a height of $10 \mathrm{~m}$. Assuming uniform mixing in the air volume, the estimated concentration of radionuclides at the point of release is shown in Table 4.1.

Table 4.4. Air activation during accelerator operation, assuming routine ventilation (although though this is not planned)

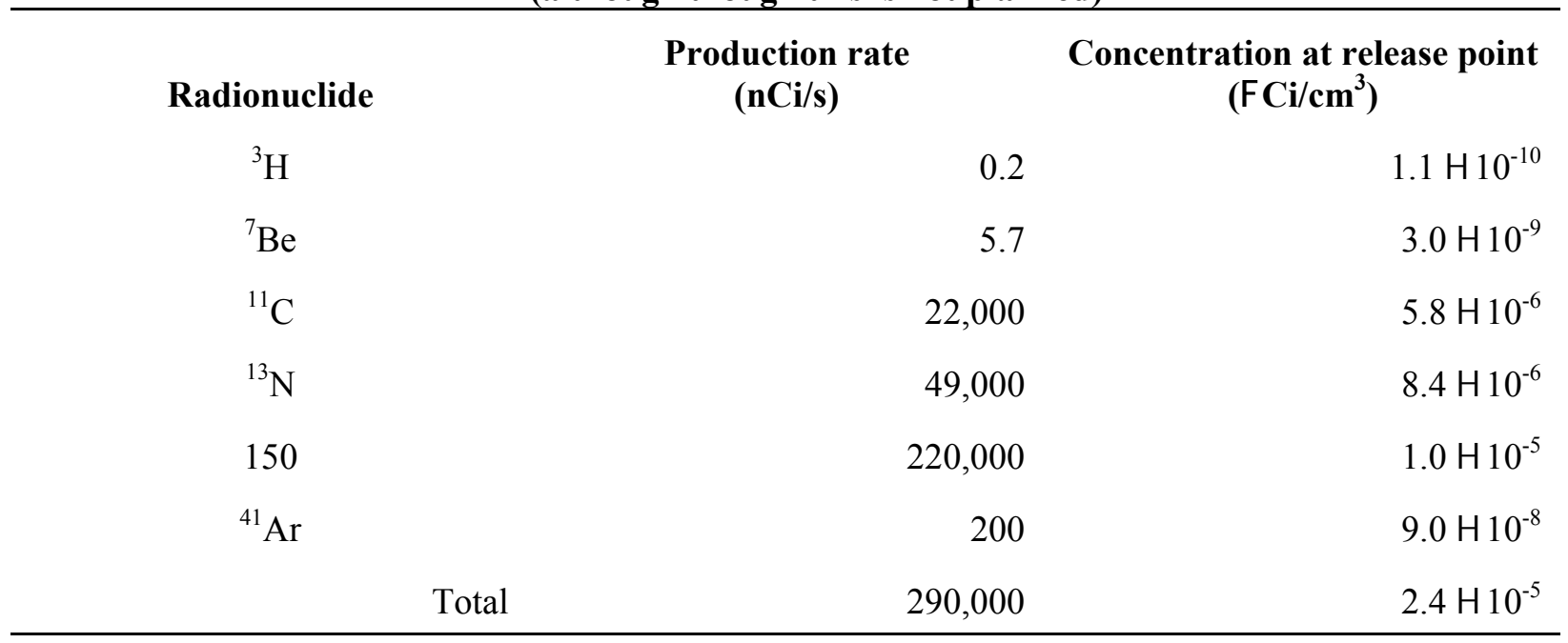

Immediately after machine operation, the concentration inside the tunnel is similar to the concentration at the release point shown in Table 4.1. Inside the tunnel, this concentration translates into $12 \mathrm{mrem} / \mathrm{h}$ for semi-infinite cloud immersion in ${ }^{13} \mathrm{~N}$ and $20 \mathrm{mrem} / \mathrm{h}$ for immersion in ${ }^{15} \mathrm{O}$. However, because these radioisotopes decay quickly, protective measures for the expected air-induced activity are not necessary. Allowing at least a 15-minute delay before entering the tunnel is the procedure. Ring operation with no exhaust increases the concentration slightly.

\subsection{REFERENCES}

Ludewig, Hans. October 1999. Preliminary Estimates of Dose following Machine Shutdown from Collimators, Vacuum Chamber Walls, and Adjacent Magnets, SNS 106100200-TR0003-R00, Lockheed Martin Energy Research, Inc., Spallation Neutron Source Activities at Brookhaven Natl. Lab. 


\section{ALARA REVIEW CONSIDERATIONS}

The objective of this review was to verify that the early stage design features of the SNS project are consistent with the design criteria in the design manual and that the design features have been set according to ALARA principles. This section describes ALARA design considerations identified and/or incorporated at the $25 \%$ design stage of the SNS project.

The primary sources of information about design features of the facility were the SNS Design Manual (LMER 1998) and the SRD applicable to the accumulator ring and transfer lines. Other sources included drawings, SNS reports, technical notes, shielding policy, and meetings with project personnel.

\subsection{CHARACTERIZATION OF RADIATION FIELDS AND POTENTIAL DOSES}

The principal sources of radiation and induced radioactivity associated with the SNS accumulator ring operation were identified. Potential doses to workers, both those working in the facility or area covered by the project and those working outside or in unrelated areas, have been assessed as appropriate to the stage of the design.

\subsection{SHIELDING}

All shielding meets the requirements of DOE regulations and applicable ALARA guidelines established for the project.

The ring has a general external shielding of $18 \mathrm{in}$. of concrete in the concrete wall and $17 \mathrm{ft}$ of earth berm outside the walls. With a design of maximum $1 \mathrm{~W} / \mathrm{m}$ uncontrolled beam loss, the resulting radiation dose at the surface of the beam would be $0.028 \mathrm{mrem} / \mathrm{h}$ for $1 \mathrm{~W} / \mathrm{m}$ uncontrolled beam loss, which is well below the design goal of $0.125 \mathrm{mrem} / \mathrm{h}$. In addition to the general earth berm, there will be local shielding inside the ring tunnel near locations of possible higher fractional beam losses. Mobile shields have been designed to fit around the beam line to provide acceptable dose levels to operating staff should higher beam losses occur. Shielding calculations for collimators have also been carried out.

Temporary or local shielding has been considered in allotting access space. Shields of a size and thickness sufficient to meet occupancy requirements outside them are based on conservative source, use, occupancy, and layout assumptions. The selected shield materials are appropriate for all types of radiation that they are to shield against. Labyrinths, labyrinth roofs, shield doors, and shield plugs or hatches have been included in the design as appropriate.

Currently, the only planned local shielding is for the collimators. None is currently planned, for example, for the injection and ejection septum magnet areas. Although the dimension and mechanical designs of the collimators are essentially the same, the radiation dose from them varies depending on function. A first estimate is that the collimators in the HEBT are - 1/10 those in the ring, those in the RTBT are $-1 / 100$ those in the ring, and those next to the target are about equal to those in the ring. There is a movable scatterer in front of the collimators in the ring. Although the function of the scatterer is to make the collimators more efficient in stopping the halo, it may be a new source of neutrons.

Movable shields in the tunnel for magnet maintenance work will be useful in reducing worker dose. Movable shields and special tools (e.g., remotely handled tool) for the alignment workers are important since these workers usually get the highest dose.

The shielding requirements caused by water activation need to be examined. Be-7 is a spallation product of water. Be-7 has a 54-day half-life and $-0.5 \mathrm{MeV}$ of gamma radiation. For example, some of the issues that need to be resolved are whether the water-cooling lines for the collimators in the ring service building need shielding and whether the water coolant in the mercury target window needs shielding. Shielding for cooling water lines also needs closer examination. 
More than $30 \mathrm{ft}$ of earth will separate the Ring Service Building from the ring, providing adequate bulk shielding. However, the radiation dose rate, from penetrations and activated cooling water, has not yet been examined at this early stage of Title I design.

\subsection{EQUIPMENT SELECTION}

A study was conducted on improving the machine lattice and the design performance of the ring. A design change request based on this study was presented to SNS management and was endorsed by the SNS Change Control Board. The new ring lattice improves the maintainability and flexibility of the machine. The new ring hybrid lattice design is expected to have lower fractional beam loss rate (10e-4, which is the design level for the ring) than the earlier focus zero defocus zero (FODO) lattice design (10e-3) because of increased beam acceptance and improved collimator efficiency.

In the RTBT beam line, a hatchway is placed above the collimators and quad doublet magnets near the target to facilitate their removal. This design is in lieu of a railroad track system that would require removal of all equipment near the target when replacing collimators or quads.

The omega HEBT, ring, and RTBT configuration now has crane coverage. This coverage will eliminate the need for personnel to be near activated equipment for repair and removal, resulting in less potential radiation exposure to workers. Overhead cranes have proven useful in keeping maintenance doses low and in moving items around when the aisles are not clear. Some components were designed to be lifted out of place and moved-with their shielding-to a low background area. This will help reduce dose during maintenance by minimizing the time spent in the high background area. Cranes, monorails, forklifts, transfer carts, etc., will have a clear path to the point of laydown.

Cap-on insulators will be used for magnet coils to lower magnet failures and, hence, require less maintenance work, reducing potential worker dose. These insulators cost - $\$ 500$ per coil for 270 magnets with two coils each.

The proton beam in the ring needs to be clean of extraneous particles so as not to activate the ejection kicker magnets and septum magnet. A "gap kicker" is needed and is present in the baseline design.

To reduce exposure to repair technicians, the magnet service building needs to include a high bay area with a crane for lifting heavy (radioactive) loads.

A number of experimental programs are under way, which will result in lower radiation exposures:

- Several epoxies for magnet conductors are being tested for breakdown in a gamma ray irradiation facility at Sandia. Lower failure rates will reduce worker exposures for repair and replacement.

- Testing similar to that for item 1 will also be conducted for insulation for magnets.

- A prototype septum injection magnet is being built and will be installed in the AGS to get experience and quantify radiation dose rates.

\subsection{ACCESS CONTROL}

The design basis was evaluated for the access control system, the radiation containment system, and the interrelated elements for these two systems (as well as the interlock network). The access control system includes beam stoppers, barriers, and an entry module at every entrance. The radiation monitoring system includes power limiting devices, shielding, dumps, collimators, etc.

The design of the PPS, as described in the SNS Design Manual, is based on SNS personnel's understanding of the "best available technology" being used at relatively new, comparable accelerator facilities. Project plans are to evaluate the use of programmable logic controllers (PLCs) as part of Title I design activities. The evaluation will address both reliability and cost-effectiveness issues. It is expected that because of system size and complexity, accelerator personnel protection functions will be implemented via PLCs. However, target and instrument personnel protection functions may be small and simple enough that a relay-based system would be more cost effective. Where PLCs are judged to offer 
the best solution, a basic reliability analysis will be performed to verify that such a system would provide the required reliability.

Risk evaluations are being performed to evaluate PPS design adequacy and worker safety and to focus attention on where system improvements can provide cost-effective risk reduction. The 1998 ASRC review recommended an early analysis by the project of the various levels of access control mapping into the floor plan of the facility. The project intends to accomplish this during Title I design.

Detectors will be installed at barriers that restrict personnel access to the tunnel during accelerator operations. Radiation detectors (ion chambers) capable of beam cutoff would also be installed at locations where disoperation of the accelerator could cause an unacceptable radiation dose. This system is designed to protect workers from prompt radiation.

A personnel entrance was added to the ring between the HEBT and RTBT so that staff will not have to enter this region from the HEBT or RTBT. This will shorten the time that personnel will have to perform maintenance on highly radioactive equipment in this area, reducing potential dose.

\subsection{RADIATION MONITORING INSTRUMENTATION}

ALARA application of the radiation monitoring instrumentation was reviewed with respect to the assumed radiation types and intensities, the nature of the facility, the need for redundancy, and the assumed normal and emergency operating conditions. This system is to protect workers from residual radiation.

"Chipmunks" are planned for use as radiation safety detectors at the SNS accelerator facilities. Another device being considered for detecting beam loss is a long (up to $25 \mathrm{ft}$ ) gas-flow ion chamber made from a section of air-insulated coax (e-mail from Gregory to Wright on SNS radiation protection instrumentation, May 7, 1999).

Gamma and neutron dosimeters will be used for both personnel and area monitoring purposes. Locations discussed for area monitoring were the klystron rooms, outside on top of the berms, at the fence line, and in the experimental areas (e-mail from Gregory to Wright on SNS radiation protection instrumentation, May 7, 1999).

Electronic alarming dosimeters, dosimeter readers, and access control stations will be installed at each controlled tunnel entrance. Automated radiological work permits (RWPs) would be highly desirable. The number of tunnel entrances that will use automated RWPs (LINAC, ring, and connecting tunnels) appears to be seven currently, and there will probably be two more restricted areas in the target basement that could also use an automated RWP system. Fixed outdoor gamma-neutron monitors and movable indoor gamma-neutron monitors will be used for area monitoring. The need for automated friskers (hand-andfoot monitors) should be evaluated for worker protection (e-mail from Gregory to Wright on SNS radiation protection instrumentation, May 7, 1999).

Real-time area monitors for outdoor use were also considered. The plan is that these monitors would indicate increased gamma and neutron fields outside the tunnel and ring berms in case a misdirected beam creates an undesirable field (not an emergency but a field that is higher than acceptable) outside the shielding. The misdirected beam would not, for some reason, be noticed either by the equipmentprotection radiation detectors (as increased radiation in the tunnels) or by beam monitors (as lost beam). These outdoor units would be located near the LINAC tuning dump and east and south of the ring. The need for radiation stack monitoring and water sampling and monitoring is also being evaluated based on potential releases (e-mail from Gregory to Wright on SNS radiation protection instrumentation, May 7, 1999).

Brookhaven National Laboratory's (BNL's) experience indicated that stationary radiation detection instrument locations are based on surveys taken as the beam is being commissioned. Estimated positions are considered as design changes are planned, but actual placement is ultimately based on surveys. Lowintensity beams are tuned through the apparatus, and then deliberate "failures" are created for evaluation purposes. BNL has found this to be the most effective method of predicting proper instrument positioning and expected radiation levels. 


\subsection{CONFINEMENT STRUCTURE AND VENTILATION SYSTEM}

The ventilation system design was reviewed against the required level of protection from airborne radioactivity, with particular attention to airflow patterns and locations of air inlets and exhausts. The exhaust system designed for the ring and transport lines has the makeup air inlet at the beginning of the HEBT and the exhaust at the end of the RTBT. There is a shielded wall between the end of the RTBT and the target. Most mechanical and piping systems for ventilation are installed underground. The makeup air and exhaust system will be turned off during operation of the accelerator and for a duration of 30 to 60 minutes afterward (duration based on monitoring of tunnel air quality and reduction of radioactivity levels). After the waiting period, the system will operate until reactivation of the accelerator.

Intake air is filtered to minimize dust accumulation in radiological areas and to exhaust filter loading. Welded seams will be used in ductwork carrying contaminated air.

The SNS central exhaust system will convey exhaust air from the tunnels, beam dumps, and Target Building to the central exhaust stack. Various ALARA design considerations are described in the SNS site utilities design. Ventilation velocity will be high enough to prevent particulate fallout within the ducts. Duct material will be butt-welded polyethylene pipe. This nonmetallic material is proposed for longevity and will require less maintenance. Wherever possible, butt welds or freeze fits will be used instead of socket welds for piping connections; this is also an ALARA practice. The exhaust stack will be located to the south of the ring tunnel. This location is central to intake points, with the consideration that it will minimize tunnel crossings.

Exhaust points will be coordinated with makeup air injection points to fully flush all areas. The design will also ensure that exhaust streams are from areas of lower potential activation to areas of higher potential activation. Each exhaust and makeup air connection to a tunnel will incorporate a $90 \mathrm{E}$ bend near the point of connection to minimize radiation streaming. Exhaust fans serving the tunnels will be separated from other systems. This will minimize potential for any cross contamination. All ductwork within the fan building will be welded stainless steel construction with flanged joints where required. The use of flange provides quick removal considering contamination buildup. All exhaust systems will be provided with redundant fan units and will be supplied from the emergency power system. It is proposed that all fan systems will run continuously, using variable frequency drives to fan capacity control, thus maintaining a constant negative static pressure in the exhaust ductwork.

Ventilation for the ring service building is separate from the ring ventilation and will be part of a local ventilation system.

Currently, there are no plans for local ventilation systems (except for local ventilation of smoke exhaust) to control localized airborne contaminants. The design approach is to keep the airborne potential to minimum and hence eliminate the need for local ventilation. The reviewers believe that when operating a beam dump area for example, it may become necessary to extract radioactive air to maintain a slight underpressure before entry can be allowed.

\subsection{CONTAMINATION CONTROLS AND DECONTAMINATION AND DECOMMISSIONING}

It is expected that no significant contamination will be present on the surface of the equipment. It is also expected that the design of the facility will require minimal maintenance, reducing the potential for internal and external dose to personnel and for contamination of the facility. However, it is possible that some surface contamination will occur as a result of a misdirected beam (scrapping), causing activated metal surfaces to become oxidized. Also, it is possible that some leakage could occur if a component is degraded or fails. Thus, testing for contamination should be conducted before maintenance. Locations that should be checked for potential contamination will be identified at later detailed design stages. 
All tunnel internal wall surfaces will be coated with epoxy to minimize erosion and the buildup of radioactivity and for ease of decontamination. Other surfaces made of nonporous material will be coated, or sealed, for ease of decontamination.

Suitable lubricants, geometries, and filters have been considered for minimizing the production and transport of particles to areas where they might become activated.

The reviewers concluded that design features to control contamination and to decontaminate are adequate at this stage of design. Provisions have also been considered to ease decommissioning, as appropriate, at this stage of design. Besides ventilation features and equipment selection, features such as decontamination enclosures, coatings, and personnel contamination monitors were studied. Radioactive waste production, storage, and movement were also considered.

\subsection{REFERENCES}

Lockheed Martin Energy Research, Inc (LMER). September 1998. Spallation Neutron Source Design Manual, Chapter 5, "Ring and Transfer Lines," Lockheed Martin Energy Research, Inc, Spallation Neutron Source, Oak Ridge, Tenn.

UT-Battelle. August 2000. SNS Site Utilities 90\% Design Package Title I Calculations, (task number: 99f-18314-1), SNS 108040000-CA-0001-R00, UT-Battelle, LLC, Spallation Neutron Source, Oak Ridge, Tenn. 


\section{RESULTS AND CONCLUSIONS}

This study found that ALARA principles are being incorporated into the SNS design. To demonstrate the application of ALARA principles, various radiological control features have been incorporated or considered at the $25 \%$ design stage for the SNS ring and transfer lines. The following ring design decisions that impact the ALARA principals were identified during this evaluation:

- The new ring hybrid lattice design will have lower beam loss than the FODO lattice design because of increased beam acceptance.

- The omega HEBT, ring, and RTBT configuration now has crane coverage, eliminating the need for personnel to be near activated equipment for repair and removal. This will result in less potential radiation exposure to workers.

- The tunnel width was increased by $2 \mathrm{ft}$ during the change to the omega configuration. This will result in less confined areas in which to work, reducing radiation exposure dose to workers.

- Features such as "quick disconnects" of electrical lines and piping are being incorporated into the design to reduce maintenance times, and hence dose levels, for maintenance personnel.

- A personnel entrance was added to the ring between the HEBT and RTBT so that personnel will not to have to enter this region from the HEBT or RTBT. This will shorten the time that personnel will need to perform maintenance work on highly radioactive equipment in this area, reducing potential dose to workers.

- In the RTBT beam line, a hatchway will be placed above the collimators and quad doublet magnets will be placed near the target to facilitate their removal. This design is in lieu of a railroad track system that would require removal of all equipment near the target when replacing collimators or quads.

- A cap-on insulator will be used for magnet coils to lower magnet failures; this will require less maintenance work and hence reduce worker dose. These insulators cost - $\$ 500$ per coil for 270 magnets with two coils each.

- A number of experimental programs are under way in support of ALARA principals: (1) several epoxys for magnet conductors are being tested for breakdown in a gamma ray irradiation facility at Sandia. Lower failure rates will reduce worker exposures for repair and replacement; (2) testing similar to that in item 1 will also be conducted for insulation for magnets; (3) a prototype septum injection magnet is being built and will be installed in AGS to get experience and quantify radiation dose rates; and (4) the AGS has extensive experience with the design and manufacture of radiationresistant beam line elements.

- $\quad$ Several movable radiation shields are being designed for use in the tunnel for magnets maintenance work. These will reduce the radiation dose to workers.

- Special tools (e.g., remotely handled tools for beam alignment workers) are being designed. These will also reduce the radiation dose to workers.

Further ALARA design considerations for various engineering disciplines are listed in Appendix A in the form of questionnaires. These ALARA considerations can assist engineers in incorporating ALARA principles into future design processes. 


\section{BIBLIOGRAPHY}

Billinton, R., and R. N. Allan. 1983. Reliability Evaluation of Engineering Systems, p. 73, New York: Plenum Press.

Johnson, J. O., et. al. January 2000. Spallation Neutron Source Beam Dump Radiation Shielding Analysis, SNS 106100200-TR0002-R00, Lockheed Martin Energy Research, Inc., Spallation Neutron Source, Oak Ridge, Tenn.

Lockheed Martin Energy Research, Inc (LMER). September 1998. Spallation Neutron Source Design Manual, Chapter 5, "Ring and Transfer Lines," Lockheed Martin Energy Research, Inc, Spallation Neutron Source, Oak Ridge, Tenn.

Ludewig, H. October 1999. Preliminary Estimate of Dose Following Machine Shutdown From Collimators, Vacuum Chamber Walls, and Adjacent Magnets, BNL/SNS Technical Note No. 067.

U.S. Nuclear Regulatory Commission (NRC). 1981. Fault Tree Handbook, NUREG-0492 NTIS, Springfield, Virg.

U.S. Nuclear Regulatory Commission (NRC). September 1981. PRA Procedures Guide, Sect. 3.6, NUREG/CR-2300, National Technical Information Service, Springfield, Virg.

UT-Battelle. November 1999. SNS Decontamination and Decommissioning Study, SNS 102030200TR0002-R00, UT-Battelle, LLC, Spallation Neutron Source, Oak Ridge, Tenn.

UT-Battelle. December 1999. SNS Environmental, Safety and Health Plan, SNS 10203000000-ES0001R00, UT-Battelle, LLC, Spallation Neutron Source, Oak Ridge, Tenn.

UT-Battelle. November 2002. SNS Parameters List, SNS 100000000-PL0001-R08, UT-Battelle, LLC, Spallation Neutron Source, Oak Ridge, Tenn.

Wei, J. October 1999. Preliminary Change Request for the SNS Ring Hybrid Lattice, BNL/SNS Technical Note No. 066.

Witkover, R. March 1999. Considerations for the SNS Ring Beam Loss Monitor System Design, BNL/SNS Technical Note No. 060.

Wright, P. June 2000. Accelerator Personnel Protection System - SRD, SNS-109090100SR0001R00, Lockheed Martin Energy Research, Inc., Spallation Neutron Source, Oak Ridge, Tenn. 
APPENDIX A

ALARA DESIGN CONSIDERATIONS 


\section{APPENDIX A: ALARA DESIGN CONSIDERATIONS}

This appendix lists other ALARA considerations that were addressed during discussion with SNS designers but that are not specifically identified in Section 5. These questions can assist engineers in incorporating ALARA principles in future design processes.

\section{A.1 RADIATION SHIELDING}

1. Have penetrations been sized and located to minimize radiation streaming?

2. Have penetrations in shielding walls been located and oriented so that accessible areas or radiationsensitive components are not in the streaming path?

3. Has streaming through penetrations for piping, conduit, ducts, etc., been reduced where appropriate by using shadow shields or shield plugs or by filling the void space in these penetrations?

4. Has local shielding been considered where possible (e.g., temporary shielding, shadow shielding, shield caps and covers)?

5. Where appropriate, are walls, ceilings, pipe hangers, and components designed to support temporary shielding?

6. If shielding is impractical, can distance be used to reduce exposure?

7. Are pieces of equipment that could produce high dose rates or contamination levels separated by shielding and distance from (a) each other, (b) equipment producing low dose rates, and (c) general access areas?

8. If piping, conduit, or ducts that pass through a room could cause a high dose rate in the room when access is required, has relocation or shielding been considered?

9. Has consideration been given to routing pipes, conduits, and ducts through labyrinths, locating radioactive pipes or other components behind columns, and embedding radioactive pipes in floors where appropriate?

10. Has consideration been given to skid-mounted systems with shielding or to adequate space for additional shielding to separate high-dose-rate-producing components from each other and from other radioactive components?

\section{A.2 EQUIPMENT SELECTION}

1. Where material might become activated, are corrosion-resistant materials and materials with low activation potential used as much as possible?

2. Are manual valve operators used only for infrequently operated valves or for those handling only low levels of radioactivity?

3. Are instruments and controls testable, with convenient connections provided for all required tests? 
4. Do the instruments selected contain the minimum amounts of fluid that could to become contaminated?

5. Are local indicators designed and located to be readable from the entry or outside of the corresponding high-dose-rate cubicle or area, perhaps by the use of mirrors or shield windows?

6. Is this an application that would justify the use of a leaded-glass window, closed-circuit TV system (or the like), or provision for their addition in the future?

7. Are vertical and straight heat exchangers used instead of horizontal or U-tube types (i.e., it is best not to have the contaminated fluid on the tube side)?

8. Are passive pieces of equipment that require little maintenance placed in the least accessible areas and separated by shielding from equipment placed in the most accessible areas and that requires frequent maintenance?

\section{A.3 ACCESS CONTROL (SPECIAL RADIOLOGICAL CONTROLS, ALARMS, INTERLOCK, ETC., ACCESSIBILITY DURING AND FOLLOWING ACCIDENTS)}

1. Have the contained, contamination, and airborne source radioactivities for the area been determined for the relevant normal, shutdown, and abnormal conditions?

2. Have radiological area designations appropriate for the expected dose rates, contamination levels, and occupancies been specified?

3. Has access control of areas, rooms, or buildings appropriate for their intended use been provided for in their design or modification?

4. Has appropriate access control during construction or modification of areas, rooms, or buildings been considered?

5. For inside and outside areas, rooms, and buildings, has consideration been given to delivery routes and loading or delivery areas?

6. Has positive physical control been provided as required for each type of radiological area?

\section{A.4 RADIATION MONITORING INSTRUMENTATION}

1. Are sampler, sample flow, and sampling line characteristics matched to the parameter(s) to be measured and to the physical characteristics of the source stream or volume to be measured?

2. Are sample probes placed in a location where sampling is isokinetic (if required) and upstream of filters (where applicable)?

3. Are sample probes in liquid streams located in a suitable flow region of the stream?

4. Are sampling systems designed for appropriate purge flow for quick, accurate samples?

5. Can sampling of high-activity streams or volumes be done remotely? 
6. Where appropriate, do hoods at sample stations or sinks operate automatically when samples are being taken?

7. Are samples (where applicable), overflows, and flush water or gas directed to drains or collectors and returned to the sampled system at some appropriate point or to the rad waste system?

8. Are air samples returned to an appropriate duct upstream of heating, ventilation, and air conditioning cleanup filters?

9. Are local sampling points minimized, with as many samples as possible routed to local sampling stations?

10. Are off-line process, effluent, and airborne monitor and sampler lines made as short as possible and heat-traced as necessary to minimize sampler line loss, water condensation, and radioactivity buildup?

11. Are monitor and sampler lines and chambers made of nonreactive materials, where appropriate, to avoid radioactivity buildup that might interfere with the proper functioning of the sensor?

12. Will a proposed modification of an area or system served by a radiation monitoring system be designed to have an insignificant effect on the performance characteristics, set points, or location of the constituent monitors or related process devices?

13. Will a proposed modification of a radiation monitoring system retain the performance characteristics, set points, or location of each of its constituent monitors or related process devices?

14. Are area radiation and airborne activity monitors provided for each area and effluent and process monitors provided for each waste stream as appropriate?

15. Are process and effluent monitors located to adequately monitor for the conditions they are designed for and to provide enough lead time for isolation or diversion of their process streams, if necessary?

16. Have portal monitors, friskers, sorting monitors, etc., been located in low-background areas or shielded as necessary?

17. Do monitors have both local and remote readouts and alarms where appropriate?

18. Can the readout of each monitoring system be recorded?

19. Does each instrument have ranges and sensitivity sufficient to ensure readout of the highest and lowest levels of activity, including accident conditions where applicable, and is the response time adequate for its function?

20. Is each monitor or monitoring system provided with a means to indicate component failure?

21. Are circuits and monitors built with fail-safe or backup capabilities?

22. Are monitors capable of being quickly and easily calibrated and tested, whether on the spot, remotely, or in some other location?

23. Are monitors qualified for the expected life doses at their locations? 


\section{A.5 CONFINEMENT STRUCTURE AND VENTILATION SYSTEM}

1. Has the air sampling design been verified as adequate for its intended purpose?

2. Is ventilation flow sufficient to keep airborne radioactivity concentrations below prescribed levels?

3. Have penetrations, gratings, construction openings, etc., been evaluated for proper placement and sealing when open to areas of potential airborne activity?

4. Are connections and thermal expansion loops on piping placed above the centerline?

\section{A.6 DECONTAMINATION AND DECOMMISSIONING}

1. Are pipe bends with a radius of 5 pipe diameters or greater used?

2. Are low points, dead legs, and flow restrictions avoided wherever possible?

3. Are there filters upstream and strainers downstream of demineralizers for the water collection system?

4. Can radioactive waste shipping containers be readily retrieved and loaded for shipment?

\section{A.7 ALARA FEATURES IN GENERAL}

1. Are systems designed for ease of maintenance, consistent with ease of inspection and operations?

2. Have maintenance requirements of systems and equipment been considered in their selection and location?

3. Have the life expectancy and reliability of systems and equipment been considered in their selection and location?

4. Have systems and equipment using radiation-resistant and environmentally resistant materials been selected where applicable?

5. Have valves been selected for low-leakage, low-maintenance, and low radioactivity accumulation properties?

6. Are similar components that require service or replacement and that may be used throughout the facility standardized where appropriate?

7. Is modular design used wherever possible (for temporary shielding, shield plugs, snap-on insulation, etc.)?

8. Where possible, are removal and installation of highly radioactive replaceable components, draining, flushing, sampling, remote survey of rad waste drums, etc., done remotely?

9. Are seals flushed, pump casings and other equipment drained, and tanks and other equipment decontaminated, as appropriate, before maintenance? 
10. Where appropriate for the use, are canned pumps used in the system, and can all pumps be maintained without removing their motors?

11. Are quick electrical, mechanical, or hydraulic release mechanisms used where possible for insulation, sample bombs, electrical connections, even entire skids, etc.?

12. Are flanges rather than welds used for quick removal where appropriate considering contamination buildup?

13. Is equipment provided with lifting lugs to reduce rigging time?

14. Has the use of special tools to facilitate maintenance been considered?

15. Have service connections been provided in high-dose-rate areas for ready use (e.g., air, water, and electrical outlets), and are they appropriate for the equipment?

16. Are isolation valves, pump motors, controls, grease fittings, removable shielding, etc., accessible in low-dose-rate areas or on the side of the wall for maintenance?

17. Are screens provided on sump pump intakes to reduce the chance of failure caused by extraneous matter?

18. Has provision been made to remotely move a frozen or entangled crane in a high-dose-rate area?

19. Have shielded containers been designed for easy receipt of filters, sample bombs, rad waste, etc.?

20. Is insulation marked to avoid unnecessary removal and for timely replacement?

21. As applicable, has consideration been given to the use of robots or robotic machines?

22. Are traffic patterns for maintenance, etc., such that movement in and out of radiological areas is efficient, with minimal crossing of paths?

23. If shielding is not practical, can equipment be moved to a lower-dose-rate area for maintenance?

24. Are the numbers of flow restrictions, vents, drains, pipe fittings, flanges, bends, and tees minimized to reduce radioactivity deposition?

25. Is adequate pull, laydown, and working space provided?

26. Are doorways and labyrinths wide enough to permit necessary personnel, component, and equipment passage?

27. Are permanent platforms, scaffolds, walkways, stairs, or ladders provided to permit accessibility, or is the area roomy and low-dose enough for the ready creation of temporary access forms?

28. Is space provided as appropriate for access areas with friskers, bins, or drums for protective clothing, etc.?

29. Is equipment designed for ready removal, with lifting lugs, pad eyes, overhead lifting points, and sufficient clearances? 
30. Are units that are frequently pulled out of their installed position for checking mounted on racks, slides, or hinges?

31. Is a hinged door rather than a cover plate used where (human) physical access is required? If there is no space for a hinged opening, is a cover plate with captive quick-opening fasteners used?

32. Is a window, guide-opening metal cover, mirror, etc., used for visual access?

33. Are components arranged so that all throw-away parts are accessible without removing other components?

34. Is proper lighting provided in the work area, and is emergency lighting provided as backup?

35. Are functions, equipment, etc., clearly and permanently labeled or provided with secure explanatory tags, and do these correspond to notations on system diagrams?

36. Have color-coding and alignment marking of equipment, systems, or areas been considered as appropriate?

37. Are hatches and manways designed to allow suitably equipped and clothed workers visibility and maneuverability?

38. Has consideration been given to the provision of lifelines to pull accidentally injured or unconscious workers from areas of high dose rates or high airborne activity?

39. Are appropriate communications provided for in the area?

40. Has sufficient speaker and siren coverage been provided so that all workers in radiological areas can be promptly alerted as to the hazards?

41. Has consideration been given to "laydown space" for portable equipment and other items used in calibrations, inspections, etc.?

42. Has consideration been given to human lifting capability in selecting equipment, temporary shielding, etc.?

43. Has the wearing of protective clothing, respirators, etc., been considered in selecting equipment for or designing areas in which temperatures may be high when workers are present?

44. Are special tools or equipment specific to one area provided and kept near the area? 
SNS 102030100-TR0001-R00

ORNL/TM-2000/206

\section{INTERNAL DISTRIBUTION}
1. M. J. Haire
5. C. H. Scott
2. J. B. Hunt
6. S. Sims
3. F. C. Kornegay
7. D. L. Williams
4. G. T. Mei
8. File-SNS DCC-RC 